\title{
Seminoma: puesta al día
}

\author{
Álvarez Moratinos B. ${ }^{1}$, Angulo Acosta S. ${ }^{1}$, Barrio Cortes J. ${ }^{1}$, García González G. ${ }^{1}$, Domínguez \\ Gordillo A. ${ }^{1}$, Alpuente Román JC. ${ }^{2}$, Moreno Reyes A. ${ }^{3}$, Cabrera Cabrera JA. ${ }^{3}$
}

Sanid. mil. 2013; 69 (1): 22-37; ISSN: 1887-8571

\begin{abstract}
RESUMEN
Objetivos: Revisar y actualizar los aspectos epidemiológicos, factores de riesgo (con especial atención a los aspectos genéticos e inmunohistoquímicos), diagnósticos y terapéuticos del seminoma. Material y Métodos: Se ha realizado una revisión de la literatura en la base de datos PUBMED, utilizando la palabra clave principal »seminoma», y los subtítulos (subheadings) «diagnóstico», «epidemiologia», «etiología», «genética, «mortalidad» y «tratamiento», sin restricciones en cuanto al tipo de estudio, seleccionando aquellos artículos considerados de interés para una revisión. La información se ha completado con otras fuentes bibliográficas como guías clínicas de referencia, registros de cáncer y tratados de Oncología y Urología. Se ha restringido la búsqueda a artículos en inglés o castellano. Así mismo se ha utilizado el Programa de Vigilancia, Epidemiología y Resultados Finales del Instituto Nacional del Cáncer (SEER) para obtener datos de incidencia y mortalidad de cáncer en los Estados Unidos, y de GLOBOCAN para los datos referentes a otros 184 países del mundo Resultados: Se han revisado un total de 3.131 artículos, con un periodo de búsqueda objeto de la revisión comprendido entre el 1 de enero de 1990 y el 31 de marzo del 2012, incluyendo un total de 51 revisiones sobre la epidemiología del tumor, 23 sobre los factores de riesgo genético, 66 revisiones sobre los distintos aspectos del diagnóstico y tratamiento, un estudio prospectivo y tres estudios randomizados, incluyéndose así mismo las directrices de 3 Guías Clínicas. Conclusiones: El tumor de células germinativas del testículo (TCGT) supone el tumor sólido más frecuente en los varones entre los 20 y 34 años, representando, el seminoma, entre el 40 y el $50 \%$ de todos ellos. Los factores de riesgo son múltiples, congénitos y adquiridos, destacándose entre ellos la predisposición familiar y bilateralidad, la criptorquidia y la acción de determinados agentes carcinógenos químicos considerados como disruptores endocrinos, que podrían favorecer el desarrollo de estos tumores. El aumento del volumen testicular y la palpación de un nódulo duro, doloroso o no, y de tamaño variable es el síntoma más frecuente de presentación. En el diagnóstico juega un importante papel la ecografía testicular y los marcadores tumorales AFP y $\beta$-hCG, sustancias onco-fetales que, además, son muy útiles en la estadificación y monitoreo de la respuesta al tratamiento. Actualmente se disponen de tres sistemas de estadificación de estos tumores que, utilizados de manera conjunta, permiten al equipo multidisciplinar realizar un tratamiento adaptado al riesgo, alcanzándose tasas de supervivencia específica superiores al $98 \%$ a los 5 años. El tratamiento del seminoma en el estadio I es la orquiectomía radical como primer gesto terapéutico, existiendo algunas discrepancias sobre el tratamiento adyuvante. Actualmente se consideran tres opciones: la vigilancia, la quimioterapia basada en derivados del platino y la radioterapia. Para los estadios II y III, las opciones tras la cirugía radical son la radioterapia con o sin quimioterapia.
\end{abstract}

PALABRAS CLAVE: Seminoma, Factores de riesgo, Genética, Inmunohistoquímica, Factores pronósticos, Quimioterapia, Radioterapia.

\section{Seminoma: an update}

SUMMARY: Objectives: To review and update the epidemiological aspects, risk factors (mainly genetic and immunohistochemical aspects), diagnosis and treatment of the seminoma. Material and Methods: A literature review has been carried out, using the keyword «seminoma» and the subheadings «diagnosis», «epidemiology», «etiology», «genetics», «mortality» and «treatment» without restrictions on types of study, selecting those articles considered of interest for a review. Information has been completed with other bibliographic references as clinical guidelines, cancer registries and Oncology and Urology texts. The search was limited to articles in English and Spanish. The Surveillance, Epidemiology and End Results Program (SEER) has also been used to obtain data on cancer incidence and mortality in the US, while GLOBOCAN was utilized to obtain data on other 184 countries. Results: A total of 3131 articles have been reviewed, covering a search period from the $1^{\text {st }}$ January 1990 to $31^{\text {st }}$ March 2012 . The search included 51 reviews on tumor epidemiology, 23 on genetic risk factors, 66 reviews on different aspects of diagnosis and treatment, a prospective study and three randomized studies, including as well the guidelines of 3 Clinical Guides. Conclusions: The germ cell tumor of the testicle (TCGT) is the most common solid tumor in males between the ages of 20 and 34, and the seminoma represents $40-50 \%$ of all of them. The risk factors are multiple, congenital and acquired, in particular familial predisposition and bilaterality, cryptorchidia and some chemical carcinogenic agents considered as endocrine disruptors that might favor the development of these tumors. The increase of testicular volume and the palpation of a hard nodule, painful or not, and of variable size is the most common initial symptom. In the diagnosis the testicular sonography and tumor markers AFP and $\beta$-hCG play an important role. These tumor markers are oncofetal substances which are besides very useful in the grading and the monitoring of the response to the treatment. Currently three grading systems of these tumors are available and their joint utilization allow adapting the treatment to the risk reaching survival rates over $98 \%$ in 5 years. The first choice treatment of the seminoma in the stadium I is radical orchiectomy although there are some discrepancies about adjuvant treatment. Currently three options are considered: surveillance, chemotherapy with platinum derivatives and radiotherapy. For stadiums II and III the options after radical surgery are radiotherapy with or without chemotherapy.

KEY WORDS: Seminoma, Risk factors, Genetics, Immunohistochemistry, Prognostic factors, Chemotherapy, Radiotherapy. 


\section{INTRODUCCIÓN}

El cáncer de testículo es un tumor infrecuente que representa solo entre el 1 y el 1,5\% de todas las neoplasias que afectan al varón, pero constituye el tumor sólido más frecuente entre los 20 y los 34 años $^{1,2}$. Se estima que $1 / 400-500$ varones desarrollará esta enfermedad antes de los 50 años. Su incidencia en EEUU y en los países occidentales se ha incrementado (entre un 3-6\% anualmente) durante los últimos 40 años $^{3-9}$, hasta duplicarse, fundamentalmente, a expensas de los estadios más precoces ${ }^{10,11}$, lo que sugiere mejoras diagnósticas en las etapas tempranas del tumor ${ }^{10}$.

El tratamiento de los pacientes con cáncer testicular ha ido evolucionando en los últimos 25 años de manera importante, y hoy por hoy, es un modelo del abordaje multidisciplinar de una neoplasia sólida maligna en donde la cirugía, la quimioterapia (basada en el cisplatino) y la radioterapia, han jugado y juegan, cada una de ellas por separado y conjuntamente, un papel decisivo en la mejora de la supervivencia desde el $60-65 \%$ en los años 60 , a más del $95 \%$ en la actualidad ${ }^{12}$.

El cáncer de testículo supone el paradigma de un tumor curable, y actualmente se siguen diseñando nuevas estrategias de tratamiento para conseguir, por un lado, una mejor supervivencia en aquellos pacientes de peor pronóstico y, por otro, intentar reducir las toxicidades tardías ${ }^{13}$.

Los tumores de células germinativas del testículo (TCGT) suponen entre el $90-95 \%$ de las neoplasias de la gónada masculina. El 5\% restante corresponde a tumores testiculares de células no germinativas, entre los que incluimos a los tumores de los cordones sexuales y del estroma gonadal (tumor de células de Leydig, tumor de células de Sertoli, tumores de la granulosa (adulto y juvenil), y gonadoblastomas, entre otros) y a los tumores del estroma inespecificos (tumores de los conductos colectores y de la rete testis y tumores del estroma inespecíficos, benignos y malignos) ${ }^{14}$. Los tumores metastásicos suponen entre 0,8 y el 2,3\% del total de los tumores testiculares ${ }^{15}$ siendo el origen más frecuente los tumores prostáticos.

De forma muy infrecuente, los TCGT se pueden localizar fuera de las gónadas, en lugares como el mediastino, retroperitoneo y sistema nervioso central, suponiendo esta situación en torno a un $10 \%$ de los $\operatorname{casos}^{16}$.

De manera práctica, podemos resumir diciendo que los TCGT se pueden dividir en dos grandes grupos histológicos: Seminomas (TCGS) y no seminomas (TCGNS).

Los TCGNS se dividen, a su vez, en cinco subtipos y, generalmente, consisten en una mezcla de estos subtipos. Además, algunos tumores se presentan como lesiones mixtas que contienen tanto elementos seminomatosos como no seminomatosos ${ }^{1,10,17}$.

La Asociación Europea de Urología (EAU) en su Guía del año 2011, aconseja clasificar a los TCGT de la siguiente manera ${ }^{14}$ :

\footnotetext{
${ }^{1}$ Universidad Complutense de Madrid. Facultad de MedicinaMadrid. España.

2 Médico Civil. Hospital Central de la Defensa Gómez-Ulla. Servicio de Urología. Madrid. España.

3 Tcol. Médico. Hospital Central de la Defensa Gómez-Ulla. Servicio de Urología. Madrid. España.
}

Dirección para correspondencia: amorrey@oc.mde.es

Recibido: 12 de julio de 2012

Aceptado: 31 de octubre de 2012
1. Neoplasia intratubular de células germinales.

2. Seminoma.

3. Seminoma espermatocítico.

4. Carcinoma embrionario.

5. Tumor del saco vitelino.

6. Teratoma (maduro, inmaduro, con componente maligno).

7. Coriocarcinoma.

8. Tumor con más de un tipo histológico (especificando componentes y $\%$ de éstos).

En este estudio nos hemos ceñido al seminoma, el cual representa el tipo histológico más frecuente de los TCGT (con un rango encontrado entre $30-60 \%)^{11,16,18-22}$.

\section{INCIDENCIA Y EDAD MEDIA}

El cáncer de testículo ocupa a nivel mundial el $18^{\circ}$ lugar en cuanto a frecuencia y el último, junto al cáncer de tiroides y al linfoma de Hodking, en cuanto a mortalidad se refiere. En el año 2008 se estima que en el mundo aparecieron 52.549 nuevos casos (una incidencia que oscila en torno al 1,5 casos por 100.000 habitantes/ año), y que 9.906 varones murieron de cáncer de testículo (en torno a 0,3 muertes por 100.000 habitantes/ año) ${ }^{23}$.

En el 2012 se estima que en EEUU se producirán 8.590 nuevos casos y 360 muertes por cáncer de testículo (una incidencia que oscila en torno a 5,5 casos por 100.000 habitantes y una mortalidad en torno a 0,2 por 100.000 habitantes por año $)^{24}$.

En el año 2008 se estima que en Europa aparecieron 18.606 nuevos casos (una incidencia que oscila en torno a 4,8 casos por 100.000 habitantes/año), y que 1.681 personas murieron de cáncer de testículo (en torno a 0,4 muertes por 100.000 habitantes/ año ${ }^{23}$. Para el mismo año se estima que en España aparecieron 698 nuevos casos (una incidencia alrededor de 2,8 casos por 100.000 habitantes/ año), y que 40 personas murieron de cáncer de testículo $(0,2 \text { muertes por habitantes/año })^{23}$, comprobándose una tendencia al alza, cuyos motivos son, en gran parte, desconocidos. Las mejores y más precoces técnicas diagnósticas ${ }^{25,26}$, y la recogida sistemática de casos en registros de cáncer pueden explicar, en cierto modo, el aumento de la incidencia. Aunque la magnitud y la consistencia de dicho aumento sugiere que otros factores como el entorno, los estilos de vida o la exposición laboral pueden estar desempeñando algún papel aun no cuantifi$\mathrm{cado}^{10}$. Son necesarias futuras investigaciones para profundizar sobre los aspectos etiológicos de este cáncer tan común en gente joven.

Las neoplasias testiculares son más frecuentes entre los blancos caucasianos ${ }^{11,19,27}$, especialmente los de los países del Norte de Europa (Suiza, Alemania, Dinamarca, Austria y Noruega) ${ }^{23}$, seguidos de indios americanos e hispanos, y son mucho menos frecuentes en asiáticos y negros ${ }^{27,28}$.

La edad media de presentación del seminoma se sitúa entre los 35 y los 40 años ${ }^{21,22,29}$, más tardía que la del TCGNS, que se sitúa entre 25-29 años ${ }^{22,30}$. Los tumores mixtos ocurren entre ambas edades. Las neoplasias testiculares por encima de los 50 años son excepcionales, y suelen corresponder a linfomas o seminomas espermatocíticos. En la infancia sólo se presentan el 2-3\% de estos tumores, con una mayor incidencia entre los 2-3 años, y la histología predominante es el tumor del seno endodérmico ${ }^{11}$. 


\section{FACTORES DE RIESGO}

La etiología es desconocida, no obstante, actualmente se reconocen algunos factores predisponentes que pueden ser clasificados en dos grandes grupos: Factores Congénitos y Factores Adquiridos.

\section{Factores de riesgo congénitos}

\section{Predisposición genética}

Los TCGT constituyen un sistema único para el estudio del mecanismo de transformación de una célula germinal totipotencial y su capacidad para obtener una línea de diferenciación embrionaria. La pluripotencialidad se manifiesta como una diferenciación histológica hacia distintos fenotipos celulares como: germinal indiferenciado (seminoma), cigótico primitivo (carcinoma embrionario), embrionario somático diferenciado (teratomas), y embrionarias diferenciadas (coriocarcinoma y tumor del saco vitelino). La comprensión de esta única histopatología se ha ampliado con recientes estudios sobre perfiles de expresión génica $^{31-34}$.

Los genes más sobreexpresados en las neoplasias de células germinales, en comparación con los genes de las células germinales sanas y células embrionarias de testículos normales, son POU5F1, NANOG, XBP1, XIST, Lin28, TFAP2C, PDPN, PRDM1, SOX17, TCL1A, y KIT. También están sobreexpresados genes con potencial oncogénico tales como MYCN y PIM2. Algunos genes asociados, propios de células madre, se expresan en seminoma y carcinoma embrionario, como POU5F1, NANOG y DPPA3, mientras que otros, como SOX2, TDGF1, FGF4, DNMT3B, sólo se encuentran en carcinomas embrionarios $^{35}$. La expresión diferencial de estos genes, que se sabe que juega un papel funcional en la auto-renovación y pluripotencialidad, puede explicar la relativa falta de potencial de diferenciación que muestran los seminomas.

Ya que el seminoma, pero no el carcinoma embrionario, conserva la expresión de KIT, TCL1A, PDPN, XIST y SOX17, es razonable sugerir que el primero pueda surgir a partir de un componente histológico invasivo, mientras que el segundo lo haría de la activación selectiva/inactivación de los genes reguladores clave del desarrollo, acompañada de una pérdida de un fenotipo PGC. Además, la iniciación aberrante de diferenciación en el linaje de carcinoma embrionario puede dar lugar a teratoma, tumor del saco vitelino, coriocarcinoma y el desarrollo, cada uno, con una única expresión génica propia ${ }^{36}$.

Se tienen datos acerca del origen genético común de los tumores germinales testiculares (TCGT) bilaterales y familiares. Se ha demostrado que polimorfismos de un solo nucleótido en o cerca de BAK1, DMRT1, TERT-CLPM1L y KITLG predisponen a tumores germinales testiculares bilaterales y familiares ${ }^{37}$. La prevalencia de tumores bilaterales se sitúa en torno al $4 \% 0^{38}$ que, si bien es una incidencia baja, no es desdeñable. La mayoría de ellos (75\%) son tumores metacrónicos y en el 80\% de los casos son seminomas ${ }^{39,40}$. El riesgo relativo de padecer un cáncer en el testículo contralateral en un paciente ya tratado de un tumor testicular, se estima, según distintos autores, entre unas 25 y 35 veces más elevado que en el resto de la población ${ }^{41,42}$. Para otros autores, el riesgo aumenta hasta 500 veces $^{43,45}$.

Los estudios epidemiológicos han referido una mayor incidencia de cáncer de testículo entre aquellos pacientes con historia familiar de TCGT (padres y hermanos), existiendo, en estos casos, un riesgo relativo de 3 a 10 veces más que en la población general $^{46}$. Así mismo, se ha demostrado una mayor incidencia entre gemelos monocigóticos. El riesgo acumulado a los 50 años de sufrir un TCGT en un hermano de un paciente afecto de esta enfermedad es del 2,2\% $\%^{39}$. Sin embargo, sólo han sido identificados un número limitado de genes susceptibles específicos para el cáncer testicular ${ }^{47,48}$.

Estudios inmunohistoquímicos han permitido demostrar una reducción en la expresión del TDRG1 (gen relacionado con el desarrollo del testículo humano 1) en sujetos con seminomas y teratomas, frente a sujetos sanos o con tumor del seno endodérmico o carcinoma embrionario. Por ello, se ha planteado la posible participación del TDRG1 como gen supresor de tumores en el contexto del seminoma ${ }^{49}$.

El descenso testicular está regulado por diversas hormonas entre las que podríamos destacar la testosterona y el péptido 3 insulin-like de células de Leydig (INSL3), el cual actúa a través de su receptor, el RXFP2 (Receptor peptídico de la familia de la relaxina 2). Se han descrito casos de criptorquidia en sujetos con mutaciones sobre el RXFP2 o el INSL3, si bien, en la gran mayoría de casos, la criptorquidia tiene una etiología multifactorial en la que influyen tanto factores genéticos como adquiridos ${ }^{50}$.

El análisis genético de los TCGT ha demostrado que, prácticamente el $100 \%$ de los tumores, muestra un incremento del número de copias del cromosoma 12p. Este marcador cromosómico se puede manifestar bien en forma de una o más copias del isocromosoma del brazo corto del cromosoma 12 (i(12p)), o bien como repeticiones en tándem de $12 \mathrm{p}$, in situ o transpuestas en otras partes del genoma (bandeo aberrante), que se han observado de forma muy temprana en el desarrollo del tumor de células germinales, sugiriendo que si no el más temprano, es uno de los primeros cambios genéticos asociados al origen de estos tumores. Aunque los genes en 12 p responsables de la patogenia aún no se han definido claramente ${ }^{51}$, estudios recientes de perfiles de expresión genética orientados a la identificación de genes asignados a 12p y sobreexpresados en los TCGT respecto a las células de testículo normal, han revelado varios candidatos con funciones en el crecimiento celular (el oncogén CCND2, el transportador de glucosa GLUT3, y la glicolítica GAPDH enzimas y TPI1), y/o en auto-renovación y pluripotencialidad (NANOG, DPPA3 y GDF3) ${ }^{34,35}$. Un clúster de genes coordinados reguladores en 12 p fue identificado como una región de $200 \mathrm{kpb}$ que comprende NANOG, DPPA3, GDF3, y otros transcriptores, que también están regulados como clusters ${ }^{34}$. Por lo tanto, una ganancia de $12 \mathrm{p}$ es multifuncional y está vinculada a la transformación, auto-renovación y al mantenimiento de la pluripotencia. También es característica la hiperdiploidía y la pérdida genética generalizada ${ }^{52-55}$.

Además de estas alteraciones genéticas, otros estudios sugieren la existencia de polimorfismos que se asocian a la patogenia de los TCGT en general, y del seminoma en particular, como los que aparecen en el gen de la DNA polimerasa gamma (POLG), consistente en una repetición del triplete $\mathrm{CAG}^{56} \mathrm{o}$ como en los 
genes del receptor tipo 3 del factor de crecimiento transformante $\beta$ (TGFBR3) y de la proteína morfogenética ósea (BMP7) pertenecientes a la vías de señalización de los factores transformantes $\beta^{57}$. No obstante el mecanismo es todavía desconocido.

También existen estudios que hablan de una distinta metilación del ADN génico asociado al cáncer testicular que se correlaciona con los distintos tipos histológicos y muestra un patrón específico tumoral en ciertos genes responsables de la heterogeneidad entre seminomas y no seminomas ${ }^{58}$.

En lo referente a la inmunohistoquímica, en los seminomas, la mayoría de marcadores tisulares están ausentes, excepto la fosfatasa alcalina placentaria (PLAP), que presenta un patrón predominante de membrana.

Por último, el Síndrome de Klinefelter, cromosomopatía en la que existe uno o más cromosomas $\mathrm{X}$ extra, se manifiesta como una insuficiencia testicular (hipogonadismo primario) y se asocia a un aumento del riesgo de padecer un tumor de células germinales ${ }^{59}$.

\section{Etnia}

Los hombres de etnia blanca tienen un riesgo entre 4,5 y 5 veces mayor que los de etnia negra para padecer un cáncer testicular, y 3 veces mayor que los asiático-americanos y que los de etnia indio-americana. Para los hombres que viven en EEUU y Europa, el riesgo de padecer esta enfermedad es mayor que para los que viven en África y Asia ${ }^{24}$.

Curiosamente, dentro de un mismo área geográfica, existen diferencias significativas entre los distintos grupos étnicos y así, en Israel, la incidencia dentro de la población judía es 8 veces mayor que en la no judía, y en Hawái la incidencia en la población filipina-japonesa es 10 veces menor que en la población china-blanca-nativa ${ }^{60}$.

\section{Criptorquidia}

En el año 1851, Le Comete describe por vez primera la asociación entre criptorquidia y el desarrollo de una neoplasia testicular ${ }^{61}$. Está demostrado que la criptorquidia constituye un riesgo potencial claramente definido de padecer un cáncer testicular $^{25,62}$. En los estudios epidemiológicos más recientes, se ha comunicado que el riesgo relativo medio de cáncer testicular en los pacientes con criptorquidia es de 5,8 $(4,3-7,8)$ veces mayor que en la población general, cifra significativamente menor del riesgo achacado a la misma históricamente ${ }^{63}$.

Entre el 5\% y el 10\% de los sujetos con antecedentes de criptorquidia, desarrolla una neoplasia en el testículo contralateral normalmente descendido ${ }^{64}$. Esto sugiere que el cáncer testicular y la criptorquidia puedan compartir factores de riesgo comunes durante el período prenatal ${ }^{65}$.

Estas circunstancias aconsejan la realización de la orquidopexia de manera temprana aun cuando no se ha podido demostrar que ésta previene de manera completa la aparición posterior de una neoplasia, sin embargo, la práctica de la misma, permite al clínico la vigilancia de una gónada no palpable anteriormente ${ }^{64}$.

En cuanto a la localización del teste criptorquídico, está plenamente aceptada la idea de que los testes en situación intraab- dominal tienen más posibilidades de desarrollar un tumor que los en situación inguinal, y en cuanto a la estirpe histológica, dichos testículos tienen mayor tendencia a desarrollar un tumor de tipo seminomatoso ${ }^{66}$.

\section{Factores de riesgo adquiridos}

\section{Hormonales}

Al principio de la séptima semana de gestación se inicia el desarrollo testicular, que depende de muchos factores, tales como la integridad cromosómica y la función endocrina normal. Una concentración anormalmente elevada de estrógenos durante las primeras fases del desarrollo embrionario se ha propuesto como causa de criptorquidia, disgenesia testicular y cáncer de testículo. Dicha exposición hormonal puede tener lugar como consecuencia de una administración exógena de estrógenos (anticonceptivos orales) o por producción fisiológica ${ }^{67}$.

En algunos estudios epidemiológicos se ha encontrado un índice de riesgo relativo del 2,8-5,3\% para el desarrollo de una neoplasia testicular en la descendencia masculina de las mujeres tratadas con dietilbestrol durante el principio del primer trimestre de gestación ${ }^{64}$.

\section{Infertilidad}

La disgenesia gonadal y la criptorquidia son malformaciones congénitas de la maduración testicular que pueden desarrollar infertilidad y cáncer testicular. Hasta tal punto es importante considerar la relación existente entre infertilidad y cáncer testicular que, actualmente, el clínico está obligado a descartar un tumor de testículo cuando es consultado por una pareja infértil. Se observan parámetros anormales en el seminograma en un gran número de casos de cáncer testicular, antes del inicio de cualquier tratamiento ${ }^{67}$. Para algunos autores, esto ocurre entre el 15-25\% de los $\operatorname{casos}^{63}$ y en otros estudios se cita la cifra del $3 \%$ de los $\operatorname{casos}^{68}$, si bien es muy difícil establecer una relación causa-efecto.

En un amplio estudio poblacional danés, se ha documentado extensamente esta circunstancia, concluyéndose que el riesgo de presentar un cáncer testicular en un varón que tiene un seminograma anormal es de 1'6 veces mayor que en la población danesa en general. Los parámetros alterados son una baja concentración de espermatozoides y una disminución de la motili$\mathrm{dad}^{69}$. Por su parte, y de acuerdo con la base de datos SEER, una evaluación realizada en Estados Unidos entre 3.800 varones que consultaron por infertilidad con alteraciones del espermiograma, mostró un aumento del riesgo de tumores testiculares de 20 veces en comparación con la población general ${ }^{70}$.

La alteración de la espermatogénesis, la criptorquidia y los tumores de células germinales, representan una gama de alteraciones del desarrollo testicular que con frecuencia están relacionados.

Skakkebaek NE et al. proponen que este espectro de alteraciones se clasifique como «síndrome de disgenesia testicular». Su hipótesis aboga por una causa común, genética o ambiental, de la criptorquidia, el hipospadia, la alteración de la espermatogé- 
nesis y el cáncer testicular ${ }^{65}$. Como ya quedó comentado anteriormente, la exposición a los estrógenos durante la vida intrauterina, representa uno de los factores propuestos como causa de las citadas alteraciones genitales masculinas.

Además, el incremento de la incidencia del cáncer de células germinales en el mundo occidental es coincidente con una disminución de la calidad del semen del hombre, lo que pudiera estar relacionado con el abuso en la utilización de sustancias químicas tales como pesticidas y fertilizantes, los cuales pueden tener acción estrogénica, así como con los estrógenos utilizados en la cadena alimentaria ${ }^{68}$.

\section{Traumatismos}

Hasta en un 4\% de los pacientes que padecen cáncer de testículo se encuentra como antecedente un traumatismo testicular de distinta intensidad ${ }^{60}$. Sin embargo no existe ninguna evidencia, ni clínica ni experimental, que apoyen la relación causa-efecto entre ambas circunstancias.

La única relación que puede existir entre ambas patologías se refiere a dos situaciones distintas. Por un lado, a la atrofia postraumática, de la cual hablaremos posteriormente, y por otro lado, a la autoexploración o exploración por parte del urólogo que tiene lugar tras haberse sufrido un traumatismo escrotal y aparecer, en el transcurso de la misma, una masa testicular de manera intercurrente.

\section{Atrofia testicular}

Desde hace varias décadas, ya se conoce la relación entre el cáncer de testículo y la atrofia testicular inespecífica o derivada de la orquitis urliana. Si bien, la hipótesis de que la atrofia testicular actúe como factor predisponente al padecimiento de un cáncer de testículo está por demostrar, sí que se ha sugerido como mecanismo etiopatogénico el desequilibrio hormonal local junto a los cambios citogenéticos degenerativos ${ }^{64}$. En la orquitis viral asociada a la parotiditis, el virus pudiera inducir la transformación maligna de manera indirecta, conduciendo a la atrofia testicular, la cual provoca una inhibición de la supresión de las gonadotropina hipofisarias (FSH, fundamentalmente), seguida de aumento de los niveles plasmáticos de las mismas, lo que conduciría a un aumento de la proliferación celular ${ }^{72}$.

\section{Agentes infecciosos}

Además de la pretendida relación existente entre el virus de la parotiditis (paramixoviridae) y el cáncer testicular ya citada anteriormente, se ha investigado aquella que pudiera existir con las enfermedades de transmisión sexual (particularmente con la infección herpética), sin que se haya podido llegar a ninguna conclusión definitiva.

Algunos trabajos hablan en favor de una relación entre la infección por el parvovirus humano B19 y el cáncer de testículo ${ }^{73}$. Sin embargo, en otros dos trabajos distintos se demuestra lo contrario ${ }^{74,75}$. Por otro lado, en algunos estudios se han encontrado títulos elevados de anticuerpos antivirus de Epstein-Barr en un $70-80 \%$ de los pacientes que padecen tumores testiculares ${ }^{76}$.

Cierta evidencia ha demostrado que los hombres infectados con el virus de inmunodeficiencia humana (VIH), en especial los que tienen el síndrome de inmunodeficiencia adquirida (SIDA), tienen un mayor riesgo a padecer seminomas ${ }^{77}$.

En definitiva, hoy por hoy es difícil conocer cuál es el papel de las infecciones en la etiopatogenia de los tumores testiculares.

\section{Agentes carcinógenos químicos}

Un gran número de agentes químicos están considerados como disruptores endocrinos, los cuales pueden jugar un papel importante en el desarrollo de los tumores. Entre los años 1981 y 1983, se detectaron 3 casos de neoplasias testiculares en personas que trabajaban en un taller de reparación de aviones, lo que llevó a la realización de un estudio más amplio encaminado a poner de manifiesto una asociación entre el desarrollo del cáncer de testículo y el hecho de trabajar en estos talleres, lo cual permitió formular la hipótesis de que una contaminación por dimetilformamida podía estar relacionada con la aparición de estos tumores ${ }^{78}$.

Diversos estudios han reflejado un incremento del riesgo de cáncer de testículo en trabajadores del metal, agricultores y mecánicos ${ }^{79-84}$. Un estudio que examinó exposiciones químicas aportó un aumento del riesgo con fertilizantes, fenoles y hu$\operatorname{mos}^{85}$. Otros grupos de trabajo, en cambio, no encontraron dicha asociación ${ }^{86-88}$, por lo que sigue siendo tema de controversia la relación existente entre los tumores testiculares y los pesticidas, cuyo interés tiene su origen en la observación de que una atrofia testicular con posterior desarrollo de seminomas ocurrió en perros militares que en la guerra de Vietnam habían estado sometidos al efecto de dichas sustancias ${ }^{89}$.

\section{Microcalcificaciones testiculares}

La microlitiasis testicular es un hallazgo sonográfico incidental, que se asocia con cierta frecuencia a patología testicular benigna (torsión testicular, criptorquidia, varicocele, síndrome de Klineferte, infertilidad, pseudo-hermafroditismo), siendo más preocupante su asociación a tumores testiculares, estimada hasta entre un 45 y $74 \%$ de casos. Si bien no se ha podido demostrar claramente la asociación entre ambas entidades, puede ser considerada como un «marcador» de una lesión disgenética que pudiera predisponer al desarrollo de un cáncer de testícu$10^{90}$. Algunos autores encuentran una fuerte asociación entre la presencia de microlitiasis en el testículo contralateral al del tumor y el desarrollo posterior de un cáncer testicular. Esta circunstancia obliga al clínico a realizar un seguimiento estrecho de estos $\operatorname{casos}^{91}$.

\section{HISTOLOGÍA. DEFINICIÓN DE SEMINOMA}

La histogénesis de los TCGT ha sido muy controvertida durante las últimas décadas, permaneciendo en la actualidad algu- 
nas dudas razonables acerca de cuáles son las líneas de desarrollo que la célula germinal sigue hasta llegar a la histopatología definitiva del tumor.

Skakkebaek, en el año 1972, describe por vez primera la presencia de una lesión precursora no invasiva con capacidad para progresar hacia un tumor de células germinales, a la que se la ha denominado neoplasia de la célula germinal intratubular $(\mathrm{NCGIT})^{92}$. Actualmente, ha quedado establecido, que salvo en los raros casos del seminoma espermatocítico y el cáncer testicular pediátrico (tumor del saco vitelino y teratoma maduro), la NCGIT es la lesión precursora de todos los tumores de células germinales ${ }^{17}$.

A nivel histológico, para considerar una neoplasia como seminoma, se requiere que exista únicamente un seminoma puro en la pieza quirúrgica y que se acompañe de unos niveles séricos normales de $\alpha$-fetoproteína (AFP), que es un marcador que aparece exclusivamente en los TCGNS.

Macroscópicamente se caracteriza por una tumoración bien delimitada, blanda, de color blanco o gris rosado, difuso o multinodular, sin formar cápsula y en la que casi nunca se ven áreas de necrosis o hemorragia ${ }^{93,94}$. El disgerminoma de ovario es el equivalente al seminoma en el sexo femenino ${ }^{59}$.

Microscópicamente podemos diferenciar tres subtipos histológicos de seminoma: el clásico, el anaplásico y el espermatocítico, y no parece que estos subtipos indiquen un pronóstico diferente ${ }^{13}$.

El seminoma clásico es, con diferencia, el más frecuente, seguido del anaplásico y del espermatocítico. Representa aproximadamente el $90 \%$ de los TCGS y es más frecuente entre los 30-40 años ${ }^{16,59}$.

Hablamos de seminoma anaplásico cuando tiene un índice mitótico elevado, células gigantes sincitiotrofoblásticas e infiltración linfocitaria. Hasta en un $20 \%$ de los casos, los niveles séricos de $\beta$-HCG estarán elevados. Constituye en torno al 10\% de los seminomas.

El seminoma espermatocítico es una variante histológica rara (2-3\% de los TCGT) que no se asocia al carcinoma in situ, a ningún otro tipo de tumor de células germinales ni a disgenesias gonadales ${ }^{95}$, tampoco se asocia a bilateralidad, no expresa fosfatasa alcalina placentaria y su potencial metastatizante es mínimo ${ }^{13}$.

\section{VÍAS DE DISEMINACIÓN}

La mayoría de autores confirma que alrededor del $80 \%$ de los seminomas están localizados en el testículo, y el restante $20 \%$, en proporción variable, corresponde a tumores con extensión regional y diseminados. La proporción de seminomas en estadio local, es significativamente mayor que en el resto de tumores testiculares, cuyas cifras rondan el 50\% $0^{18,20,21}$.

Inicialmente presenta una diseminación linfática. El drenaje linfático primario del testículo es hacia los ganglios retroperitoneales situados entre D11 y L4, caudal a los vasos renales, debido a su común origen embriológico con el riñón. Estos ganglios discurren adyacentes a la aorta y a la vena cava inferior, habiéndose demostrado por linfografía, la interconexión desde el lado derecho al izquierdo, siendo más infrecuente en sentido contra- rio. En el ascenso de la enfermedad, si el tumor es del lado izquierdo, nunca cruza al lado derecho, pero si es del lado derecho, puede cruzar al lado izquierdo ${ }^{96}$. Entre un $15-20 \%$ de pacientes tienen afectación ganglionar bilateral. Se consideran patológicos los ganglios de más de $10 \mathrm{~mm}$. Los tumores derechos metastatizan primero en los ganglios interaortocava, mientras que los izquierdos drenan en los paraaórticos. Por último, los ganglios lumbares retroperitoneales, a través del conducto linfático, drenan en los linfáticos del mediastino y fosa supraclavicular y ocasionalmente en los axilares ${ }^{16}$.

Las metástasis hematógenas son más tardías a la afectación de los ganglios mediastínicos y supraclaviculares, y son principalmente pulmonares, pero también hepáticas, óseas o cerebrales.

\section{CLÍNICA}

\section{Aumento del volumen testicular}

Es sin duda el síntoma más frecuente y aparece entre el 70\% y el $90 \%$ de los $\operatorname{casos}^{66}$. Se pone de manifiesto por la aparición de un nódulo o masa, generalmente indoloro y de superficie irregular, duro, que aumenta de tamaño de manera progresiva y que el paciente descubre accidentalmente durante el aseo, actividad sexual o tras un traumatismo escrotal de intensidad

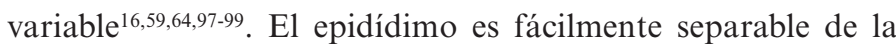
misma $^{96}$.

\section{Dolor}

Puede manifestarse como una sensación de pesadez, o dolor sordo ${ }^{99}$. En un $10 \%$ de los pacientes, el dolor puede ser agudo como consecuencia de una hemorragia intratumoral ${ }^{16,59,64,96}$. Para Sandeman ${ }^{100}$, el seminoma crece de manera más indolente, y esta forma de presentación se daría solo en un 38\% de los casos, por lo que el diagnóstico precoz es más difícil.

\section{Infertilidad}

Se trata este de un apartado importante para el clínico dado que se piensa que hasta un $40-60 \%$ de los pacientes con cáncer testicular son subfértiles en el momento del diagnóstico. Es por ello por lo que ante un varón que consulta por infertilidad, el Urólogo está obligado a descartar, entre otras patologías, el tumor de testículo. La causa de infertilidad en estos pacientes tiene un origen múltiple (enfermedad sistémica subyacente, afectación testicular contralateral, fenómenos autoinmunes u hormonales, e incluso por afectación psicológica $)^{67}$.

\section{Otros síntomas}

La ginecomastia, en ocasiones dolorosa (mastodinia), puede considerarse como una manifestación endocrina sistémica de estas neoplasias, y puede aparecer hasta en un $7 \%$ de los $\operatorname{casos}^{100}$. Se explica por la producción de gonadotrofina coriónica huma- 
na (HCG) y es más frecuente en el coriocarcinoma siendo más rara en el ca. embrionario, teratocarcinoma y seminoma ${ }^{67}$.

El hidrocele aparece entre un $10 \%$ y un $15 \%$ de los casos y a veces puede enmascarar la presencia de un tumor testicular, dificultando o retrasando el diagnóstico ${ }^{101}$.

\section{Síntomas derivados de la presencia de metástasis}

Alrededor de un $10 \%$ de los casos se manifiestan por síntomas diversos debidos a la presencia de metástasis en distintos órganos. Entre estos cabe destacar ${ }^{63}$ :

- Síntomas respiratorios como tos, hemoptisis y disnea.

- Síntomas digestivos como anorexia, náuseas, vómitos, distensión abdominal y hemorragias digestivas.

- Presencia de adenopatías, generalmente a nivel supraclavicular, en donde puede palparse sin dificultad o bien a nivel retroperitoneal ocasionando compresión extrínseca de los vasos ilíacos o de la cava, provocando edemas de ambos miembros inferiores.

- Dolor óseo de origen metastásico.

- Dolor lumbar inespecífico ocasionado por infiltración linfática retroperitoneal (con compresión del psoas o de raíces nerviosas). Este es el síntoma extragonadal que con mayor frecuencia se observa ${ }^{59,96}$.

- Manifestaciones del sistema nervioso central y periférico (por compromiso cerebral, medular o de raíces periféricas).

- Trombosis de la cava o de los vasos ilíacos que provocan edemas de los mmii.

\section{Asintomático}

Sin embargo hasta en un $10 \%$ de casos el tumor es asintomático siendo un hallazgo incidental o encontrándose de forma inesperada, tras pequeños traumatismos o intervenciones sobre un testículo con otra patología. Es por ello que el autoexamen periódico en pacientes de alto riesgo, así como la exploración genital por personal médico especializado son de vital importancia de cara a detectar precozmente masas testiculares ${ }^{10,16,59,96,97}$.

\section{DIAGNÓSTICO}

\section{Historia clínica y exploración}

Ante un paciente con sospecha de cáncer testicular lo primero que debemos realizar es una historia clínica completa. La edad y los antecedentes familiares son datos fundamentales dada la mayor prevalencia en gente joven y por la ocasional agregación familiar ${ }^{59,97,102}$. En los casos con base genética demostrada, la edad de presentación es de dos a tres años inferior ${ }^{102}$. La clínica ya ha sido referida ampliamente en el apartado anterior.

En cuanto a la exploración, debe seguirse la sistemática indicada por todos los tratados de propedéutica y así deberán examinarse ambos escrotos, ambas regiones inguinales, el abdomen, las mamas y el cuello ${ }^{63,66}$.

Con respecto al escroto, tras realizar una inspección adecuada, se pasará a la palpación bimanual de ambos testes, co- menzando siempre por el sano. En el caso de un tumor testicular, palparemos en cualquier región del mismo un nódulo de tamaño variable, duro y generalmente indoloro, de superficie irregular y no adherido a planos superficiales. Ocasionalmente, la presencia de un hidrocele reactivo puede dificultar la palpación. Por último, se palparán ambos cordones espermáticos y la exploración finalizará con la transiluminación de la bolsa escrotal, que nos permitirá descubrir la presencia de un hidrocele reactivo. Toda lesión de consistencia firme y dura dependiente del testículo debe ser considerada un tumor, mientras no se demuestre lo contrario ${ }^{64}$.

Las regiones inguinales, el abdomen y el cuello, deben explorarse en busca de adenopatías.

Por su parte, las mamas deben explorarse en busca de ginecomastia. Recíprocamente, hay que recordar que siempre que un paciente acuda a su médico refiriendo ginecomastia o mastodinia, los testículos deben ser explorados sistemáticamente en busca de un tumor.

El diagnóstico diferencial debe realizarse con procesos inflamatorios como la orquitis u orquiepididimitis, con la torsión testicular, hidrocele, varicocele y espermatocele ${ }^{16,96,99}$, siendo la orquiepididimitis el diagnóstico erróneo más frecuente ${ }^{103,104}$.

\section{Diagnóstico por imagen}

\section{Ecografía escrotal bilateral}

Tiene una especificidad del 95\%. Confirma la presencia de una lesión intratesticular, y diferencia muy bien entre dichas lesiones y las de localización paratesticular ${ }^{105}$, sin embargo, puede ser difícil diferenciar tumores (malignos o benignos) de lesiones inflamatorias ${ }^{106}$. En cuanto a la semiología ecográfica, lo tumores seminomatosos aparecen como lesiones sólidas, hipoecóicas, homogéneas, sin calcificaciones ni áreas quísticas ${ }^{64}$ mientras que los tumores no seminomatosos se visualizan como masas hipoecogénicas, heterogéneas, mal delimitadas, con zonas quísticas y áreas de necrosis ${ }^{107}$.

\section{Radiografía de tórax}

Resulta útil a la hora de valorar las metástasis pulmonares y las lesiones mediastínicas, si bien actualmente se encuentra superada en cuanto a sensibilidad por el TAC torácico ya que este detecta lesiones desde $3 \mathrm{~mm}$ de tamaño mientras que la radiografía solo detecta lesiones mayores de $10 \mathrm{~mm}^{66,96}$.

\section{Tomografía axial computarizada (TAC) toraco-abdominopélvica}

La principal indicación del TAC es la estadificación y posterior seguimiento, para valoración de la respuesta al tratamiento. Cuando se utiliza en combinación con la determinación de los marcadores tumorales, alcanza una efectividad del $80 \%-90 \%{ }^{108}$. Su utilidad radica en la detección de metástasis en pulmón y en los órganos abdominales y, sobre todo, en la detección de adenopatías retroperitoneales inferiores a $10 \mathrm{~mm}$, las cuales deben ser consideradas como sospechosas de malignidad $^{16,97,109}$. 


\section{Resonancia Magnética (RM)}

La RM escrotal posee una sensibilidad del 100\% y una especificidad del 95\%-100\% para el diagnóstico de los tumores testiculares, ofreciendo unos resultados similares al TAC a la hora de evaluar adenopatías retroperitoneales, sin embargo, su elevado coste no justifica su uso rutinario para el diagnóstico y seguimiento de estos pacientes, quedando como un método de reserva ${ }^{66}$.

\section{Tomografía con emisión de Positrones (PET)}

No ha demostrado ventaja alguna sobre los estudios por TAC a la hora de evaluar los ganglios linfáticos retroperitoneales ${ }^{110}$.

\section{Diagnóstico de laboratorio y marcadores tumorales}

\section{Hemograma y estudio bioquímico}

Los resultados de las determinaciones de estos parámetros sanguíneos son inespecíficos, sin embargo, en caso de estar alterados nos orienta hacia una valoración más precisa del estado general del paciente. Así, en casos de enfermedad avanzada, puede existir un cuadro de anemia de intensidad variable. La elevación de las cifras de urea y creatinina orientan hacia un cuadro de uropatía obstructiva por compresión de adenopatías retroperitoneales, y por último, una alteración de las pruebas hepáticas nos ponen en aviso sobre la presencia de metástasis en el hígado ${ }^{96}$.

\section{Marcadores tumorales}

De acuerdo con su estructura y comportamiento bioquímico, los marcadores del cáncer testicular se clasifican en tres categorías:

1. Marcadores citogenéticos o cromosómicos.

2. Marcadores moleculares.

3. Marcadores séricos o proteicos.

\section{Marcadores citogenéticos o cromosómicos}

Se detectan por estudios cariotípicos o por técnicas de análisis molecular sobre tejidos tumorales cultivados en medios de crecimiento rápidos. En los tumores testiculares adquiere especial interés las alteraciones sobre el cromosoma 12 (sobre todo la existencia del isocromosoma del brazo corto del cromosoma 12 (i (12p)) ya que es altamente específica como prueba diagnóstica. Se observa en el $89 \%$ de los tumores seminomatosos y en el $81 \%$ de los tumores no seminomatosos ${ }^{52-54}$. El i (12p) es, por lo tanto, patognomónico de los tumores de células germinales testiculares en todos los tipos histológicos. En casi todos ellos existe un número excesivo de copias de $12 p$, bien en forma de i (12p), bien como un aumento de $12 \mathrm{p}$ en cromosomas con bandeo aberrante. Pero el gen o los genes en $12 \mathrm{p}$ responsables de la patogenia aún no se han definido ${ }^{11}$.

\section{Marcadores moleculares}

Aquí se incluyen los oncogenes y genes supresores del tumor implicados en el proceso de iniciación y progresión del tumor.
Los oncogenes más frecuentemente encontrados en los tumores de testículo son el N-ras, C-Ki-ras, C-Kit y el Hst- ${ }^{36}$.

\section{Marcadores séricos o proteicos}

Los tumores de testículo son neoplasias productoras de proteínas marcadoras, fácilmente medibles mediante radioinmunoensayo (RIA), y capaces de detectar cantidades pequeñas de tumor ( $10^{5}$ células). La determinación sérica de dichas proteínas es útil para el diagnóstico, estadificación y monitoreo de la respuesta al tratamiento, sin embargo, ninguna de ellas es suficientemente específica como para ser empleada como método de cribado o de diagnóstico sin histología en el cáncer de testículo. Pertenecen a dos clases, las sustancias oncofetales asociadas al desarrollo embrionario (AFP, $\beta$-hCG) y las enzimas celulares (LDH y FAP o fosfatasa alcalina placentaria) ${ }^{64}$.

1) Sustancias oncofetales:

AFP: La Alfa Feto Proteína es una glicoproteína sérica de vida media entre 5 y 7 días. La producen el carcinoma embrionario puro $(70 \%)$, el teratocarcinoma, el tumor del saco vitelino $(75 \%)$ y los tumores mixtos, pero no el coriocarcinoma ni el seminoma puro ${ }^{64,66}$.

$\beta$-hCG: La fracción beta de la Gonadotrofina Coriónica Humana es una glicoproteína cuya vida media es de 24 a 36 horas. Se eleva en los coriocarcinoma (100\%), en los carcinomas embrionarios (40\%-60\%) y en los seminomas puros (5\%-10\%). Puede también elevarse en otros cánceres como el de hígado, páncreas, pulmón, mama, riñón y vejiga ${ }^{64,66}$.

2) Enzimas celulares:

LDH: La Láctico Deshidrogenasa es una enzima presente en todas las células del organismo, por lo que es poco específica. La determinación de una de sus isoenzimas (LDH I-IV) puede ser útil en el monitoreo del tratamiento del seminoma puro avanzado $^{111}$. Sus niveles parecen tener una correlación directa con el tamaño del tumor ${ }^{112}$.

GTP: La Gamaglutamiltranspeptidasa se encuentra elevada en un tercio de los pacientes que presentan seminomas activos ${ }^{113}$.

FAP: La Fosfatasa alcalina placentaria, es una isoenzima fetal que se encuentra elevada en el $100 \%$ de los seminomas en estadio avanzado ${ }^{66}$.

\section{Aplicación clínica de los marcadores tumorales en el seminoma}

Actualmente no existe ningún marcador que supere la alta sensibilidad y la especificidad de la AFP y de la $\beta$-hCG. Cuando éstos se encuentran elevados en el suero hay que pensar en la existencia de un tumor de testículo con casi absoluta seguridad. Por el contrario, la ausencia de tasas elevadas de los mismos no excluye la existencia de un cáncer de testículo ${ }^{75}$.

Ambos marcadores permiten delimitar la heterogenicidad tumoral en lo que se refiere al tipo histológico, de manera que del $50 \%$ al $70 \%$ de los pacientes con tumores testiculares no seminomatosos presentan niveles elevados de AFP, y del $40 \%$ al $60 \%$, niveles elevados de $\beta$-hCG. Calculando ambos marcadores de forma simultánea, alrededor del $90 \%$ de los pacientes presentan elevaciones de una o ambas sustancias marcadoras ${ }^{114,115}$.

Con respecto al seminoma, la determinación de una AFP elevada sugiere con firmeza la presencia de un componente no 
seminomatoso y como tal debe ser tratado (aunque no se encuentre en el espécimen anatomopatológico) ya que nunca se eleva en los seminomas puros. Por otro lado, entre un 5 y un $10 \%$ de pacientes con seminoma puro presentan una elevación discreta de la $\beta$-hCG debido a la presencia de células gigantes sincitiotrofoblásticas ${ }^{64}$.

\section{ESTADIFICACIÓN}

La importancia de la estadificación no debe ser subestimada, ya que de ella va a depender, por un lado, la toma de decisiones terapéuticas y, por otro, nos va a proporcionar datos pronósticos importantes. Con esta idea, en la práctica clínica se barajan tres sistemas de estadificación: el sistema TNM, el sistema de estadificación basado en factores pronósticos del cáncer de células germinativas metastásico (IGCCCG) y el estudio de los factores de riesgo anatomopatológico pronósticos de enfermedad oculta (estadio I).

\section{Sistemas de estadificación}

En 1997 se publicó un consenso internacional sobre la clasificación aplicable a los TCGT. La estadificación del American Joint Committe on Cancer (AJCC) emplea por vez primera una categoría con marcador sérico tumoral (S) para completar los estadios pronósticos definidos sólo por la anatomía (TNM) ${ }^{64}$. Actualmente se recomienda el sistema de estadificación TNM del 2009, que es el que se especifica en la tabla 1 y que incluye la categoría $\mathrm{S}$ (niveles séricos de los marcadores tumorales) $)^{116}$.

Para la extensión tumoral se emplea también la clasificación del SEER modificada por la $\mathrm{AJCC}^{117}$ en la que se describen los siguientes estadios:

- Estadio I: El cáncer testicular en etapa I está limitado al testículo, no extendiéndose a los ganglios linfáticos ni a órganos a distancia.

- Estadio II: La enfermedad se extiende a los ganglios linfáticos regionales, retroperitoneales o paraaórticos, generalmente en la región del riñón, pero siempre subdiafragmáticos.

- Estadio III: Implica propagación más allá de los ganglios retroperitoneales y/o diseminación a otros órganos a distancia.

Su correspondencia con la clasificación TNM se expone en la tabla 2.

En 1997, el International Germ Cell Cancer Collaborative Group (IGCCCG) definió un sistema de estadificación basado en factores pronósticos del cáncer de células germinativas metastásico consistente en la identificación de algunos factores adversos independientes clínicos ${ }^{118}$. Este sistema de estadificación se ha incorporado a la clasificación TNM y emplea la histología, la localización del tumor primario, la localización de las metástasis y las concentraciones séricas de marcadores antes de la quimioterapia, como factores pronósticos para clasificar a los pacientes en grupos de pronóstico «bueno», «intermedio» o «malo» ${ }^{116,117} \mathrm{y}$ que expone en la tabla 3.

En la tabla 4 se exponen los factores de riesgo anatomopatológicos pronósticos de enfermedad metastásica oculta ${ }^{119-121}$.
Por último, como Factores de riesgo anatomopatológicos pronósticos de enfermedad metastásica oculta (estadio I) distinguimos:

a) Seminomatoso

- Tamaño del tumor $(\geq 4 \mathrm{~cm})$

- Invasión de la rete testis

b) No seminomatoso

- Invasión vascular/linfática o peritumoral

- Tasa de proliferación (MIB-1) $\square 70 \%$

- Porcentaje de carcinoma embrionario $\square 50 \%$

\section{FACTORES PRONÓSTICOS}

\section{Histología}

El seminoma es el tumor germinal que muestra mejores tasas de supervivencia. Los tumores no seminomatosos tienen un comportamiento más agresivo. De hecho, la histología es el factor con mayor utilidad desde el punto de vista pronóstico ${ }^{19}$.

El mejor pronóstico de los seminomas viene determinado por su lento crecimiento, por su sensibilidad a la radioterapia, así como por su respuesta espectacular a la quimioterapia ${ }^{19}$.

El subtipo histológico de seminoma parece no influir en el pronóstico final, si bien es cierto que el seminoma anaplásico se diagnostica en estadios más avanzados que el clásico y ello implica un peor pronóstico ${ }^{19}$. Otros factores como el índice mitótico elevado (en los seminomas anaplásicos) o la presencia de infiltración linfocitaria tampoco parecen influir.

\section{Características tumorales}

Determinados seminomas con un fenotipo clínico atípico (tales como metástasis viscerales, niveles elevados de $\beta$-hCG y/o enfermedad recurrente) presentan un peor pronóstico. Estas formas atípicas presentan tratamiento específico con determinados regímenes de quimioterapia (QT) (como cisplatino, paclitaxel e ifosfamida) al ser resistentes frente a la QT convencional $^{122}$.

\section{Estadio}

La supervivencia relativa a los 5 años del seminoma es muy alta tanto en el estadio I como el II (99,5\%, 95,9\% respectivamente), si bien, las cifras caen cuando nos referimos al estadio III $(78,5 \%)$. La supervivencia a los 5 años para todos los estadios es $91,3 \%{ }^{19}$. Hoy, el cáncer testicular, es considerado una de las neoplasias sólidas más curables ${ }^{123}$.

\section{Tamaño}

En pacientes diagnosticados en estadio I de la enfermedad, la supervivencia relativa es más alta en aquéllos con tumores menores de $5 \mathrm{~cm}(100 \%)$ comparado con los que la masa era igual o superior a dicho tamaño $(97,8 \%)^{19}$. 
Tabla 1. Clasificación TNM.

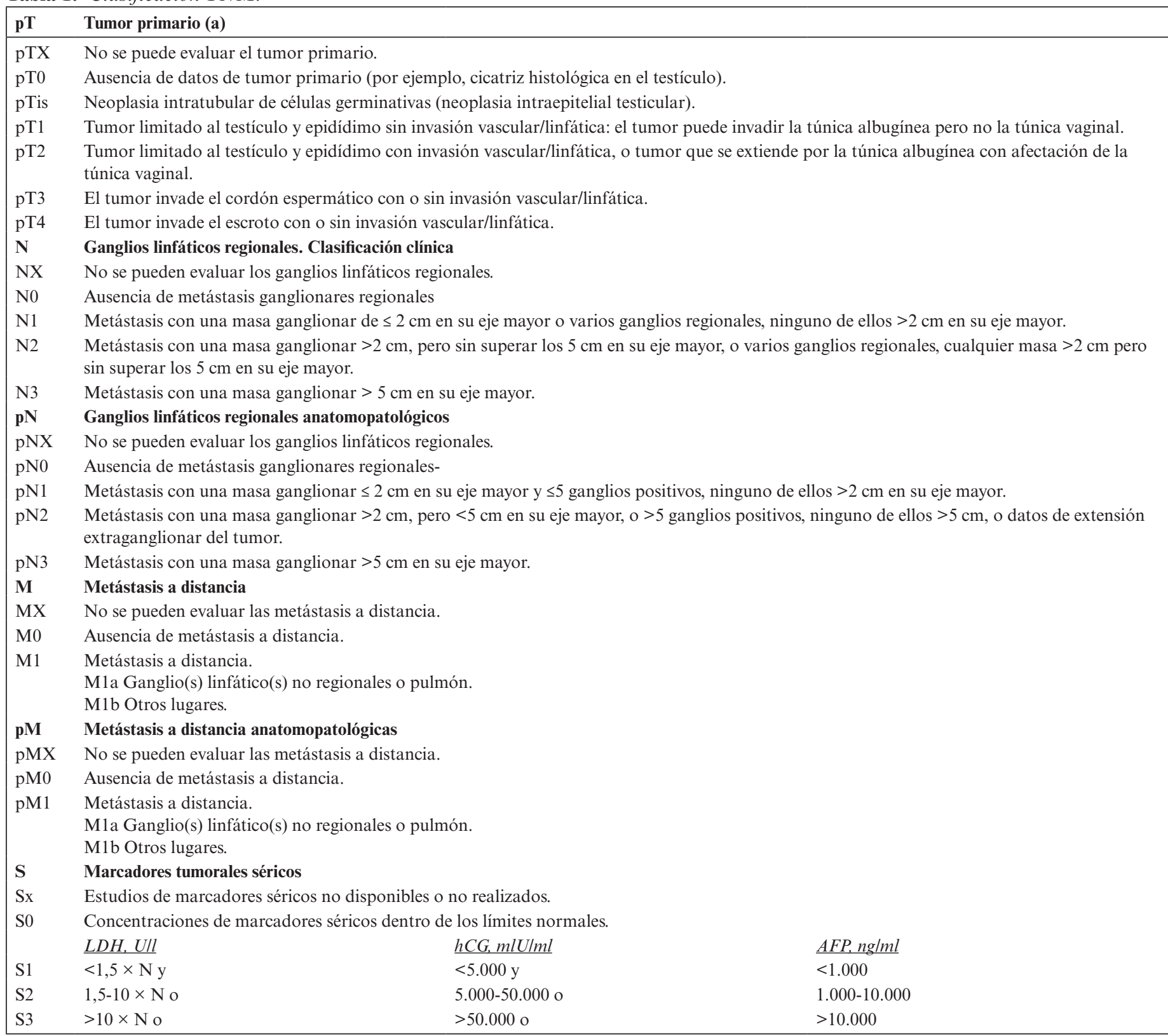

AFP: alfafetoproteína; hCG: gonadotropina coriónica humana; LDH: lactato deshidrogenasa; N: límite superior de la normalidad para el análisis de LDH.

(a): Salvo en el caso de pTis y pT4, en los que no siempre es necesaria una orquiectomía radical con fines de clasificación, la extensión del tumor primario se clasifica tras la orquiectomía radical; véase pT. En otras circunstancias se utiliza TX cuando no se ha realizado una orquiectomía radical.

\section{Edad al diagnóstico}

Los hombres con edades entre 20 y 49 años tienen una supervivencia ligeramente superior a los hombres mayores de 50 años. El estadio en el momento del diagnóstico es similar en gente joven frente a la gente de mayor edad y no puede justificar estas diferencias ${ }^{19}$.

\section{Raza}

La supervivencia es ligeramente inferior en varones de etnia negra frente a los de etnia blanca. Si bien es cierto que los tumores en población de etnia negra se diagnostican en estadios más avanzados, también lo es que al comparar supervivencia en etnia negra y etnia blanca en tumores del mismo estadio, se aprecia una menor supervivencia en la etnia negra ${ }^{19}$.

\section{Nivel educativo y socioeconómico}

Recientes estudios sugieren que el bajo nivel educativo y socioeconómico se asocia a un peor pronóstico y mayor mortalidad en los pacientes con cáncer testicular. Ello es debido, en gran parte, al retraso diagnóstico y terapéutico que se observa en estos grupos. Éste constituye el principal motivo de la mayor mortalidad observada en países con menor nivel socioecono$\operatorname{mico}^{124}$. 
Tabla 2. Agrupación por estadios y relación con la clasificación TNM.

\begin{tabular}{|lll|}
\hline Estadío & & \multicolumn{1}{c|}{ Clasificación TNM } \\
\hline I & & pTis N0 M0 S0 \\
I & & pT1-4 N0 M0 Sx \\
& IA & pT1 N0 M0 S0 \\
& IB & pT2-4 N0 M0 S0 \\
& IS & pT1-4 N0 M0 S1-3 \\
II & & pT1-4 N1-3 M0 Sx \\
& IIA & pT1-4 N1 M0 S0-1 \\
& IIB & pT1-4 N2 M0 S0-1 \\
& IIC & pT1-4 N3 M0 S0-1 \\
III & & pT1-4 N0-3 M1 Sx \\
& IIIA & pT1-4 N0-3 M1a S0-1 \\
& IIIB & pT1-4 N0-3 M0-1a S2 \\
& IIIC & pT1-4 N0-3 M0-1b S0-3 \\
\hline
\end{tabular}

\section{Estado civil}

El estado civil es un factor pronóstico independiente en el caso de los tumores testiculares. Se ha demostrado que las mejores supervivencias en el caso de las neoplasias testiculares corresponden a hombres casados frente a los solteros ${ }^{125}$.

\section{Retraso en el inicio del tratamiento}

El retraso desde el reconocimiento de la lesión hasta la terapia definitiva (orquiectomía) varía desde 3 a 6 meses y se correlaciona con la aparición de metástasis ${ }^{96,103}$. Además, el retraso es mayor en el caso de los seminomas ( 5 meses) frente a los no seminomas ( 3 meses) ${ }^{126}$. Las causas de dicho retraso pueden atribuirse bien al paciente (dependientes del nivel educativo y socioeconómico como ya se comentó antes), bien al médico (error en el diagnóstico, generalmente diagnosticándose una epididimitis). El retraso en el diagnóstico en la era de la quimioterapia no repercute sobre la supervivencia específica, pero si en la morbilidad, ya que al ser diagnosticada la enfermedad en estadios más avanzados, los gestos terapéuticos son más agresivos ${ }^{103,104}$.

\section{Mejoras diagnósticas y terapéuticas}

Gracias a las mismas, la supervivencia a los 5 años se ha incrementado en Reino Unido desde el 46\% en 1968 hasta el 92\% en 1999. Este incremento ha sido más marcado en el caso del seminoma (supervivencia del 91\%) frente a los no seminomas $(77 \%)^{10}$.

Tabla 3. Sistema de estadificación basado en el pronóstico del cáncer de células germinativa_metastático

\section{Grupo de buen pronóstico}

No seminomatoso ( $56 \%$ de los casos)

SSP a los 5 años del 89\%

Supervivencia a los 5 años del $92 \%$

\section{Seminomatoso $(90 \%$ de los casos)}

SSP a los 5 años del $82 \%$

Supervivencia a los 5 años del $86 \%$

\section{Grupo de pronóstico intermedio}

No seminomatoso ( $28 \%$ de los casos)

SSP a los 5 años del 75\%

Supervivencia a los 5 años del $80 \%$

Seminomatoso (10\% de los casos)

SSP a los 5 años del $67 \%$

Supervivencia a los 5 años del $72 \%$

Grupo de mal pronóstico

No seminomatoso (16\% de los casos)

SSP a los 5 años del $41 \%$

Supervivencia a los 5 años del $48 \%$

Seminomatoso

Ningún paciente clasificado como de mal pronóstico
Todos los criterios siguientes:

Primario de testículo/retroperitoneal

Ausencia de metástasis viscerales extrapulmonares

AFP $<1.000 \mathrm{ng} / \mathrm{ml}$

$\mathrm{CG}<5.000 \mathrm{IU} / 1(1.000 \mathrm{ng} / \mathrm{ml})$

$\mathrm{DH}<1,5 \times \mathrm{LSN}$

Todos los criterios siguientes:

Cualquier localización primaria

Ausencia de metástasis viscerales extrapulmonares

AFP normal

Cualquier hCG

Cualquier LDH

Todos los criterios siguientes:

Primario de testículo/retroperitoneal

Ausencia de metástasis viscerales extrapulmonares

AFP 1.000-10.000 ng/ml, o

CG 5.000-50.000 IU/1, o

DH $1,5-10 \times$ LSN

Cualquiera de los criterios siguientes:

Cualquier localización primaria

Metástasis viscerales extrapulmonares AFP normal

Cualquier hCG

Cualquier LDH

Cualquiera de los criterios siguientes:

Primario mediastínico

Metástasis viscerales extrapulmonares

AFP $>10.000 \mathrm{ng} / \mathrm{ml}$, o

hCG $>50.000 \mathrm{IU} / 1(10.000 \mathrm{ng} / \mathrm{ml})$, o

$\mathrm{DH}>10 \times \mathrm{LSN}$

AFP: alfafetoproteína; hCG: gonadotropina coriónica humana; LDH: lactato deshidrogenasa; LSN: límite superior de la normalidad; SSP: supervivencia sin progresión. 


\section{TRATAMIENTO DEL SEMINOMA}

El tratamiento de los tumores de células germinativas del testículo está condicionado por dos factores: la variedad histológica del tumor y el estadio en el que se encuentre.

Actualmente contamos con tres armas terapéuticas para combatir a los tumores testiculares: la cirugía, la radioterapia externa y la quimioterapia.

\section{Cirugía}

\section{Orquiectomía radical}

La orquiectomía radical vía inguinal, con la ligadura del cordón a nivel del orificio inguinal profundo, representa la terapia de inicio ante cualquier tipo de tumor testicular, salvo raras excepciones. Es común a todos los estadios tumorales ${ }^{75,127}$.

\section{Linfadenectomía retroperitoneal}

Por su parte, la linfadenectomía retroperitoneal (LRP) tiene como objetivo la resección de los ganglios linfáticos que intervienen como primer relevo en la diseminación del tumor (región de la cava, paraaórticos y del hilio renal correspondiente), estando reservada como segunda línea de actuación quirúrgica. Puede realizarse vía abierta (por medio de una laparotomía clásica) o bien por vía laparoscópica. Actualmente, se realiza en aquellos casos en que la quimioterapia no ha logrado tratar completamente las adenopatías retroperitoneales. Conlleva la pérdida de la eyaculación si no se hace una cirugía con conservación nerviosa ${ }^{67}$.

\section{Radioterapia Externa}

La radioterapia externa está considerada como un tratamiento local encaminado a destruir las células cancerosas localizadas a nivel de las adenopatías retroperitoneales. Actualmente, con la planificación basada en imágenes TAC y la planificación $3 \mathrm{D}$, se consigue una mejor delimitación del volumen a irradiar y una mejor protección de los órganos de riesgo, disminuyendo así la toxicidad ${ }^{128}$. Entre los efectos indeseables (poco frecuentes) cabe destacar la diarrea, los calambres abdominales y el cansancio. Las complicaciones potenciales a largo plazo incluyen obstrucción intestinal, úlceras, toxicidad pulmonar, cardiaca y la aparición de segundos tumores radioinducidos ${ }^{13}$.

\section{Quimioterapia}

La quimioterapia, actualmente, ocupa un lugar ineludible en el conjunto del tratamiento del cáncer de testículo, siendo la responsable, sin lugar a dudas, del alto índice de curación alcanzado en el tratamiento de estos tumores ${ }^{66}$. De manera distinta a lo citado para la radioterapia, el tratamiento con quimioterápicos es un tratamiento sistémico, por lo que es eficaz contra aquellas células tumorales localizadas tanto en las adenopatías retroperitoneales como en las metástasis de los distintos órganos a distancia.
Los principales medicamentos utilizados en distintos regímenes terapéuticos son el cisplatino, la bleomicina, la vinblastina, la ciclofosfamida, el etopósido y el paclitaxel.

Las principales combinaciones o regímenes terapéuticos son el BEP (bleomicina, etopósido y cisplatino), EP (etopósido y cisplatino) y el VIP (ifosfamida, etopósido y cisplatino).

Entre los efectos secundarios de la quimioterapia se incluyen la caída del pelo, anorexia, nauseas, vómitos, desarrollo de infecciones, astenia, neuropatías, insuficiencia renal, aparición de segundos tumores (leucemias) y cardiopatías.

\section{Tratamiento del seminoma según el estadio}

\section{Estadio I}

Al hacer una revisión de la literatura, nos encontramos con posturas encontradas a la hora de tomar una decisión sobre qué pauta seguir en este estadio del tumor tras haber realizado la orquiectomía radical, ya que no existe un tratamiento estandarizado $^{129}$. Las tres opciones válidas son: la vigilancia (seguimiento o «surveillance»), la quimioterapia adyuvante o la radioterapia adyuvante.

Los argumentos a favor de la vigilancia son, que menos del 15 al 20\% de los enfermos van a presentar recidivas ${ }^{130}$ (por lo que se estaría sobretratando a un $80 \%$ de pacientes), que en caso de aparecer recidiva, existen tratamientos de rescate que pueden controlar la enfermedad sin impacto sobre la supervivencia global, y por último, que se evita la toxicidad aguda y crónica, y sobre todo no se producirían tumores radioinducidos ${ }^{131}$.

Los argumentos en contra son, que la quimioterapia (dos ciclos de carboplatino) reduce la tasa de recidivas del $6 \%$ al $1-3 \%{ }^{132,133}$, que la radioterapia es un tratamiento que ha demostrado su eficacia y seguridad (el seminoma es un tumor muy radiosensible), que es fácil de administrar, que es poco costosa, disponible en la mayoría de los centros, con resultados reproducibles y que presenta pocos efectos secundarios ${ }^{13}$.

La controversia llega hasta el punto de que, en la Guía Clínica sobre el cáncer de testículo de la EAU del año 2011, se recomienda como primera opción la vigilancia (si se dispone de instalaciones y se confía en la fidelidad del paciente a un seguimiento estrecho durante 5 años al menos) ${ }^{14} \mathrm{y}$, sin embargo, para otros autores que así mismo han revisado la bibliografía, la vigilancia es la opción menos recomendada por el alto coste y el estrés que supone para los enfermos ${ }^{13}$.

Llegados a este punto, es necesario hablar del concepto de «tratamiento adaptado al riesgo» ${ }^{126}$, según el cual, la actitud que se debe tomar va a depender de los «factores de riesgo de recidiva», con el objetivo fundamental de reducir al mínimo la morbilidad derivada del tratamiento.

Estos factores tampoco se han establecido con claridad, ya que en la serie del Hospital Royal Marsden ${ }^{135}$ el único factor de riesgo histológico confirmado es la presencia de invasión vascular y/o linfática, para Von der Masse $\mathrm{H}$ et al ${ }^{135}$ el factor de riesgo decisivo es el tamaño tumoral superior a $6 \mathrm{~cm}$, para Warde ${ }^{119}$ son el tamaño superior a $4 \mathrm{~cm}$ y la invasión de la rete testis, y para Choo $\mathrm{R}$ et $\mathrm{al}^{136}$, el único factor valorable, es la invasión de la rete testis. 


\section{B. Álvarez Moratinos, et al.}

En la Guía Clínica sobre el cáncer de testículo de la EAU del año $2011^{14}$ se establecen como factores de riesgo para el seminoma los ya citados en párrafos anteriores: el tamaño tumoral igual o superior a $4 \mathrm{~cm}$ y la invasión de la rete testis.

En seminomas en estadio I de «bajo riesgo» $(<4 \mathrm{~cm}$, sin invasión de la rete testis) ${ }^{119}$ la vigilancia activa puede ser una opción segura ${ }^{14}$. Para el resto de casos en estadio I, hay grupos de trabajo que muestran que entre la QT y la RT adyuvante no se aprecian diferencias significativas en cuanto a la tasa o tiempo de recidiva, ni en la supervivencia ${ }^{137-139}$. Y en cambio, sí se ha detectado un mayor riesgo de toxicidad a largo plazo, como un riesgo aumentado de neoplasias secundarias malignas ${ }^{140,141}$ y acontecimientos cardiovasculares $^{141,142}$, atribuidos a la radiación y, en parte, a los tratamientos de quimioterapia recibidos. Si consideramos la temprana edad de diagnóstico y la larga esperanza de la vida de la mayor parte de los pacientes con cáncer testicular, estos aspectos cobran aun mayor relevancia. Por ello, y en vista de la información publicada acerca de la toxicidad a largo plazo, ya no se recomienda la radioterapia como tratamiento adyuvante de primera línea para los pacientes con seminoma en estadio clínico $\mathrm{I}^{14,29}$

Los pacientes en estadio I de «alto riesgo» deben recibir QT adyuvante (dos ciclos de carboplatino), pues la tasa de recidiva se reduce a la mitad que cuando se opta por vigilancia ${ }^{133}$.

Es probable que los pacientes estén recibiendo tratamiento excesivo, como lo sugiere el éxito de la curación en casi el 100\% de los pacientes con seminoma en estadio I, independientemente del tratamiento que se utilice (RT adyuvante, QT adyuvante o vigilancia), y una tasa de recaída del $15-20 \%$ en las grandes series de vigilancia sin tener en cuenta los factores de riesgo. Por lo tanto, la decisión terapéutica debería ser compartida con un paciente informado.

\section{Estadio II}

El abordaje terapéutico, en este caso, se realiza clasificando la enfermedad en dos grandes grupos: enfermedad no voluminosa, y enfermedad voluminosa o bulky, definida esta última como el tumor (adenopatía) con un diámetro máximo mayor de $5 \mathrm{~cm}$ definido en el TAC.

\section{Enfermedad no voluminosa (No bulky o estadio II A/B)}

Puede ser tratado inicialmente con radioterapia adyuvante sobre las cadenas ganglionares paraaórticas e ilíacas homolaterales (campo en palo de hockey) ${ }^{143}$. Como alternativa al tratamiento con radioterapia, puede emplearse la quimioterapia según los esquemas BEP 3 ciclos o Cisplatino- Etopóxido 4 ciclos $^{144}$.

\section{Enfermedad voluminosa (bulky $>5 \mathrm{~cm}$ o estadio II C)}

En este caso, el tratamiento de elección es la quimioterapia adyuvante según los esquemas BEP 3 ciclos en los pacientes de «buen pronóstico» según los criterios del IGCCCG, o 4 ciclos en los pacientes de «pronóstico intermedio» o de «mal pronóstico» ${ }^{14}$. Se puede optar también por Cisplatino- Etopóxido 4 ci$\operatorname{clos}^{13}$.
Las masas residuales, tras el tratamiento adyuvante con QT o RT, deben ser controladas mediante FDG-PET y marcadores tumorales. Las masas que sean menores de $3 \mathrm{~cm}$ serán susceptibles de observación (ya que puede tratarse, por ejemplo, de tejido necrótico y son masas fibróticas); en caso de ser mayores de $3 \mathrm{~cm}$ se realizará una $\mathrm{PET}$ ante el riesgo de tumor viable. Si no fuera posible realizarla, o si la PET resulta positiva, se extirpará dicha masa y se llevará a cabo un tratamiento adyuvante si fuera necesario ${ }^{145,146}$.

\section{Estadio III}

El tratamiento recomendado es la quimioterapia adyuvante con esquemas que incluyan cisplatino: BEP; Cisplatino-Etopóxido; Cisplatino-Vimblastina-Bleomicina; Vimblastina-Ifosfamida-Cisplatino ${ }^{147,148}$.

Las masas residuales deben ser consideradas y tratadas tal como se han comentado para el estadio III ${ }^{149,150}$.

En caso de tumores bilaterales, la orquiectomía radical bilateral es también el tratamiento recomendado, pero conlleva infertilidad y dependencia de testosterona exógena, causando muchos problemas psicológicos. Si bien en casos seleccionados, hay una alternativa que es la orquiectomía parcial. Esta opción presenta muy buenos resultados oncológicos y la no dependencia a testosterona exógena, aunque sigue siendo frecuente la infertilidad secundaría ${ }^{151}$.

\section{CONCLUSIONES}

Los TCGT, y más concretamente el seminoma, son actualmente el paradigma de un tumor curable cuando es abordado para su tratamiento de una manera multidisciplinar. El retraso en el diagnóstico y tratamiento de estos tumores no supone, en la era de la quimioterapia, un contratiempo serio a la hora de valorar los resultados de la supervivencia específica, pero sí debemos insistir en que este retraso puede repercutir sobre la morbilidad de nuestros pacientes, ya que los gestos terapéuticos, necesariamente, tendrán que ser más agresivos al encontrarnos la enfermedad en estadios más avanzados. En cuanto a los factores de riesgo, sigue vigente aún la teoría propuesta por Skakkebaek, según la cual, hay un espectro de alteraciones, entre las que se encuentran la criptorquidia, la infertilidad, el hipospadia y los TCGT, denominado "síndrome de disgenesia testicular», que pudieran tener el mismo origen, entre otros, la exposición del feto a los estrógenos durante la vida intrauterina, sin olvidar la acción de algunos agentes químicos exógenos entre los que se encuentran los pesticidas. El análisis genético de los TCGT ha demostrado que, prácticamente el $100 \%$ de los tumores, muestran un incremento del número de copias del cromosoma $12 \mathrm{p}$. Clínicamente, toda lesión de consistencia firme y dura dependiente del testículo debe ser considerada un tumor mientras no se demuestre lo contrario. En el diagnóstico juega un importante papel la ecografía testicular que tiene una especificidad del $95 \%$, siendo el TAC tóraco-abdominopélvico la mejor prueba de imagen para detectar adenopatías retroperitoneales y metástasis en otros órganos. La determinación de una AFP elevada sugiere con firmeza la presencia de un componente no seminomatoso 


\section{Seminoma: puesta al día}

y, entre un 5 y un $10 \%$ de pacientes, presentan una elevación discreta de la $\beta$-hCG y la Fosfatasa alcalina placentaria (FAP) se encuentra elevada en el $100 \%$ de los seminomas en estadio avanzado. El estadiaje del tumor se lleva a cabo empleando tres clasificaciones: la TNM, el Sistema de estadificación basado en el pronóstico del cáncer de células germinativas (IGCCCG) y los factores de riesgo anatomopatológicos pronósticos de enfermedad metastásica oculta en el estadio I.

En cuanto al tratamiento, una vez realizada la orquiectomía radical, existe controversia acerca de cómo actuar posteriormente en el estadio I, ya que se puede optar, por la vigilancia, radioterapia o quimioterapia; en el estadio II A/B, la radioterapia adyuvante es el tratamiento de elección, y en el estadio IIC y III, la quimioterapia adyuvante, que incluya derivados del platino, juega un papel fundamental.

\section{BIBLIOGRAFÍA}

1. Sarma AV, Mclaughlin JC, Schottenfeld D. Testicular cancer. En: Epidemiology of cancer. 3ed Edition. New York Oxford University Press 2006; 1151.

2. Bray F, Sankila R, Ferlay J et al. Estimates of cancer incidence and mortality in Europe in 1995. Eur J Cancer 2002; 38: 99-166.

3. Toledano MB, Jarup L, Best $\mathrm{N}$ et al. Spatial variation and temporal trends of testicular cancer in Great Britain. Br J Cancer 2001; 84:1482-7.

4. Power DA, Brown RS, Brock CS et al. Trends in testicular carcinoma in England and Wales, 1971-99. BJU Int 2001; 87:361-5.

5. Cuninkova M, Ondrus D, Plesko I et al. Epidemiology of testicular tumors in Slovakia (1993-1997): Preliminary report. Int Urol Nephrol 2001; 32:669-75.

6. McGlynn KA, Devesa SS, Sigurdson AJ et al. Trends in the incidence of testicular germ cell tumors in the United States. Cancer 2003; 97:63-70.

7. Huyghe E, Matsuda T, Thonneau P. Increasing incidence of testicular cancer worldwide: A review. J Urol 2003; 170:5-11.

8. Gudbjartsson T, Magnusson K, Bergthorsson $\mathbf{J}$ et al. A population based analysis of increased incidence and improved survival of testicular cancer patients in Iceland. Scand J Urol Nephrol 2003; 37:292-8.

9. Bray F, Ferlay J, Devesa SS et al. Interpreting the international trends in testicular seminoma and nonseminoma incidence. Nat Clin Pract Urol 2006; 3:532.

10. Xu Q, Pearce MS, Parker L. Incidence and survival for testicular germ cell tumor in young males: A report from the Northern Region Young Person's Malignant Disease Registry, United Kingdom. Urol Oncol 2007 Jan; 25(1):32-7.

11. Germà-Lluch JR, Aparicio Urtasún J, Pilulats Rodriguez. Tumores germinales gonadales. En: Tratado de Oncología. Barcelona: Publicaciones Permanyer 2009; 99-102.

12. Sheinfeld J. Prefacio. Urol Clin N Am 2007; 34.

13. López Carrizosa MC, Rodríguez Pérez A, Sáez Garrido J. Tumores testiculares: Diagnóstico y tratamiento. Urología Integrada y de Investigación 2007; 12(2):145-156.

14. Albers P, Albrecht W., Algaba F. et al. Guía clínica sobre el cáncer de testículo de la EAU: actualización de 2011. Actas Urol Esp 2012; 36:127-145

15. Shrevaskumar R, Patel R, Richardson, RL et al. Metastatic cancer of the testis: a report of 20 cases and review of the literature. J. Urol 1989; 142:1003.

16. Bosl GJ, Bajorin DF, Sheinfeld J, Motzer RJ, Chaganti, RSK. Cancer of the testis. In: DeVita VT, Lawrence TS, Rosenberg SA, eds. Cancer: Principles and Practice of Oncology. 8th ed. Philadelphia, Pa: Lippincott-Raven 2008; 1463-1485.

17. Michael E. Karellas, Ivan Damjanov, Jeffery M. Holzbeierlein. Neoplasia de la célula germinal intratubular de los testículos, biopsia testicular contralateral y cáncer bilateral de testículo. Urol Clin N Am 2007; 34: 119-125.

18. Fernández Gómez JM, Guate Ortiz JL, Martín Huescar A et al. Presentación clínica del cáncer germinal de testículo. Arch Esp Urol 2002; 55(8):915-922.

19. Biggs ML, Schwartz S. SEER Survival Monograph. Cancer Survival Among Adults: U.S. SEER Program, 1988-2001. Chapter 21. Cancer of the testis.

20. Germà-Lluch JR, García del Muro X, Maroto $P$ et al. Clinical pattern and therapeutic results achieved in 1490 patients with germ cell tumours of the testis: the experience of the Spanish Germ Cell. Cancer Group. Eur Urol 2002; 42:553-63.
21. Diz Rodríguez, R et al. Tumores testiculares: Evaluación de la experiencia durante 25 años en un hospital militar. Actas Urol Esp, Mayo 2005, vol.29, no.5, p.457-464. ISSN 0210-4806.

22. Tomomasa H, Shimizu H, Sato S et al. Clinical study of testicular germ cell tumors. Hinyokika Kiyo 2001 Jun; 47(6): 389-395.

23. Ferlay J, Shin HR, Bray F, et al. GLOBOCAN 2008 v2.0, Cancer Incidence and Mortality Worldwide: IARC CancerBase No. 10 [Internet]. Lyon, France: International Agency for Research on Cancer; 2010. Disponible en: http://globocan.iarc.fr

24. American Cancer Society. Cancer Facts \& Figures 2012. Atlanta: American Cancer Society; 2012. Disponible en: http://www.cancer.org/acs/groups/content/@epidemiologysurveilance/documents/document/acspc-031941.pdf

25. Zheng T, Holford TR, Ma Z et al. Continuing increase in incidence of germcell testis cancer in young adults: Experience from Connecticut, USA. 19351992. Int J Cancer 1996; 65:723-9.

26. McKiernan JM, Goluboff ET, Liberson GL et al. Rising risk of testicular cancer by birth cohort in the United States from 1973 to 1995. J Urol 1999; 162:361-3.

27. Altekruse SF et al. SEER Cancer Statistics Review, 1975-2007, National Cancer Institute. Bethesda, MD, Disponible en: http://seer.cancer.gov/ csr/1975-2007/, based on November 2009 SEER data submission, posted to the SEER web site, 2010.

28. Walsh TJ, Davies BJ, Croughan MS, Carroll PR et al. Racial differences among boys with testicular germ cell tumors in the United States. J Urol. 2008 May; 179(5):1961-5.

29. Warde P, Gospodarowicz MK, Banerjee D et al. Prognostic factors for relapse in stage I testicular seminoma treated with surveillance. J Urol 1997; 157(5):1705-1709.

30. Swerdlow, AJ: Epidemiology of testicular cancer. Principles and practice of genitourinary oncology. Raghavan D, Scher HI, Leibel SA y Lange P. Lippincott-Raven. Philadelphia 1997; 643.

31. Almstrup K, Hoei-Hansen CE, Wirkner U et al. Embryonic stem cell-like features of testicular carcinoma in situ revealed by genome-wide gene expression profiling. Cancer Res 2004; 64:4736.

32. Almstrup K, Hoei-Hansen CE, Nielsen JE et al. Genome-wide gene expression profiling of testicular carcinoma in situ progression into overt tumours. Br J Cancer 2005; 92:1934.

33. Juric D, Sale S, Hromas RA et al. Gene expression profiling differentiates germ cell tumors from other cancers and defines subtype-specific signatures. Proc Natl Acad Sci USA 2005; 102:17763.

34. Korkola JE, Houldsworth J, Chadalavada RS, et al. Down-regulation of stem cell genes, including those in a $200-\mathrm{kb}$ gene cluster at $12 \mathrm{p} 13.31$, is associated with in vivo differentiation of human male germ cell tumors. Cancer Res 2006; 66:820.

35. Houldsworth J, Korkola JE, Bosl GJ, et al. Biology and genetics of adult male germ cell tumors. J Clin Oncol 2006; 24:5512.

36. Korkola JE, Houldsworth J, Dobrzynski D et al. Gene expression-based classification of nonseminomatous male germ cell tumors. Oncogene 2005; 24:5101.

37. Kratz CP, Han SS et al. Variants in or near KITLG, BAK1, DMRT1, and TERT-CLPTM1L predispose to familial testicular germ cell tumour. J Med Genet. 2011 Jul;48(7):473-6.

38. Dieckmann KP, Loy V, Büttner P. Prevalence of bilateral testicular germ cell tumours and early detection based on contralateral testicular intra-epithelial neoplasia. 1993 Mar;71(3):340-5.

39. Heidenreich A, Weissbach L, Holtl W, Albers P, Kliesch S, Dieckmann K. Organ sparing surgery for malignant germ cell tumor of the testis. J Urol 2001; 166: 2161-5.

40. Soto Delgado M, Pedrero Márquez G, Ramírez Chamorro F, et al. Neoplasia testicular bilateral sincrónica. Presentación de un nuevo caso. Actas Urol Esp 2007; 31(1): 58-60.

41. Michel E. Karellas, MD; Ivan Damjanov, MD, PhD, Jeffery M. Holzbeierlein, MD. Neoplasia de la célula germinal intratubular de los testículos, biopsia testicular contralateral y cáncer bilateral de testículo. Urol Clin N Am 34. 2007: 119-125.

42. Osterlind A, Berthelsen JG, Abildgaard N, et al. Risk of bilateral testicular germ cell cancer in Denmark: 1960-1984. J Natl Cancer Inst 1991; 83:1391-1395.

43. Fossa S, Chen J, Schonfeld S, et al. Risk of contralateral testicular cancer: a population-based study of 29515 U.S. men. J Natl Canc Inst 2005; 97 (14): 1056-66.

44. Sokal M, Peckham Mj, Hendry WF. Bilateral germ cell tumors of testicle. Br J Urol 1980; 52: 158-62. 
45. Heidenreich A, Bonfig R, Derschum W, et al. A conservative approach to bilateral testicular germ cell tumors. J Urol 1995; 153: 10-3.

46. Dieckmann KP, Pichlmeier U. Clinical epidemiology of testicular germ cell tumors. World J Urol. 2004 Apr; 22(1):2-14.

47. Lutke-Holzik MF, Rapley EA, Hoekstra HJ et al. Genetic predisposition to testicular germ-cell tumors. Lancet Oncol 2004; 5:363-71.

48. Horvath A, Korde L, Greene MH et al. Functional phosphodiesterase 11A mutations may modify the risk of familial and bilateral testicular germ cell tumors. Cancer Res 2009; 69:5301-6.

49. Chen HY, Wen JM et al. Expression of human testis development related gene 1 in testicular cancer detected by tissue microarray. Zhonghua Nan Ke Xue. 2010 Oct; 16(10):883-6.

50. Bay K, Main KM et al. Testicular descent: INSL3, testosterone, genes and the intrauterine milieu. Nat Rev Urol 2011 Apr; 8(4):187-96.

51. Korkola JE, Houldsworth $\mathrm{J}$ et al. Molecular events in germ cell tumours: linking chromosome-12 gain, acquisition of pluripotency and response to cisplatin. BJU Int. 2009 Nov;104(9 Pt B):1334-8.

52. Rodríguez E, Houldsworth J, Reuter VE et al. Molecular cytogenetic analysis of $\mathrm{i}(12 \mathrm{p})$-negative human male germ cell tumors. Genes Chromosomes Cancer 1993; 8 (4):230-6.

53. Bosl GJ, Ilson DH, Rodriguez E et al. Clinical relevance of the i(12p) marker chromosome in germ cell tumors. J Natl Cancer Inst 1994; 86 (5):349-55.

54. Mostert MC, Verkerk AJ, van de Pol M et al.: Identification of the critical region of $12 p$ over-representation in testicular germ cell tumors of adolescents and adults. Oncogene 1998; 16 (20):2617-27.

55. Van Echten J, Oosterhuis JW, Looijenga LH et al. No recurrent structural abnormalities apart from i(12p) in primary germ cell tumors of the adult testis. Genes Chromosomes Cancer 1995; 14 (2): 133-44.

56. Blomberg Jensen M, Leffers $\mathrm{H}$ et al. Association of the polymorphism of the CAG repeat in the mitochondrial DNA polymerase gamma gene (POLG) with testicular germ-cell cancer. Annals of Oncology 2008; 19: 1910-1914.

57. Dalgaard MD, Weinhold N, Edsgärd D, Silver JD et al. A genome-wide association study of men with symptoms of testicular dysgenesis syndrome and its network biology interpretation. J Med Genet. 2012 Jan; 49(1):58-65.

58. Brait M, Maldonado L, Begum S et al. DNA methylation profiles delineate epigenetic heterogeneity in seminoma and non-seminoma. Br J Cancer 2012 Jan 17; 106(2):414-23.

59. Robert J Motzer, George J Bosl. Testicular Cancer in: Harrison’s Principles of internal Medicine 18th Edition. July 23; 2004, pag.:1045.

60. Oliver RTD. Epidemiology of testis cancer. In: Comprehensive text-book of genitourinary oncology. Vogelzang, Scardino, Shipley an Coffey Eds., Wilians and Wikins, Baltimore, USA 1996; 923-931.

61. Grove JS. The cryptorchid problema. J Urol 1954; 71:735-41

62. Husmann DA. Cryptorchidism and its relationship to testicular neoplasia and microlithiasis. Urology 2005; 66:424.

63. J.M. Cózar, M. Tallada, E. Espejo. Etiopatogenia, historia natural y clínica de las neoplasias testicul In: Tratado de Oncología Urológica. $1^{\text {a }}$ ed., L. Resel Estévez, J. Moreno Sierra, Sanidad y Ediciones S.L. 2003; 935-1037.

64. Richie JP. Neoplasms of the testis. In: Campbell Urology. 8th ed., Walsh, Retik, Stamey and Vaughan, eds., WB Saunders Co., Philadelphia 2002; 3147-3219.

65. Skakkebaek NE, Raipert-De Meyts E, Main KM. Testicular dysgenesis syndrome: An increasingly common developmental disorder with environmental aspects. Hum Reprod 2001; 16:972-8.

66. Domínguez Bravo C et al. Etiología In: Tumores testiculares. Ed. Visto Bueno Equipo Creativo, S.L. 2007, 11-14, 23-26, 40, 51-77.

67. Lambert S., Fisch H. Infertilidad y cáncer testicular. Urol Clin N Am 34 2007.269-277.

68. Lange PH. Fertility issues in germ cell testicular tumor. In: Testicular Malignance Update. Postgraduate course. AUA1996.

69. Jacobsen R, Bostofte E, Engholm G et al. Risk of testicular cancer in men with abnormal semen characteristics: cohort study. BMJ 2000; 321:789-92.

70. Raman JD, Nobert CF, Goldstein M. Increased incidence of testicular cancer in men presenting with infertility and abnormal semen analysis. J Urol 2005; 174:1819-22.

71. Bay K, Asklund C, Skakkebaek NE, et al. Testicular dysgenesis síndrome: possible role of endocrine disruptors. Best Pract Res Clin Endocrinol Metab 2006; 20(1): 77-90.

72. Bear CM, Benson MC, Kelalis PP, The incidence and outcome of mumps orchitis in Rochester, Minnesota, 1935-1974. Mayo Clin Proc 1977; 52: 3-7.
73. Ergunay K, Tezel GG, Dogan Al, et al. Testicular persistence of parvovirus B19: evidence for preferential infection of germ cell tumors. Pathol Res Pract. 2008; 204(9):649-53. Epub 2008 Jun 9.

74. Diss TC, Pan LX, Du MQ, et al. Parvovirus B19 is associated with benign testes as well as testicular germ cell tumours. Mol Pathol 1999 Dec; 52(6): 349-54.

75. Tolfvenstam T, Papadogiannakis N, Andersen A, Akre O. No association between human parvovirus B19 and testicular germ cell cancer. J Gen Virol 2002 sep; 83(Pt9):2321-4.

76. Holl K, Surcel HM, Koskela P, et al. Maternal Epstein-Barr virus and cytomegalovirus infections and risk of testicular cancer in the offspring: a nested case-control study. Oulu, Finland. APMIS. 2008 Sep;116(9):816-22.

77. Goedert JJ, Purdue MP, McNeel TS, et al. Risk of germ cell tumors among men with HIV/acquired immunodeficiency syndrome. Cancer Epidemiol Biomarkers Prev 2007; 16 (6):1266-9.

78. Ducatman Am, Conwill De, Crawl C. Germ cell tumors of the testicle among aircraft repairmen. J Urol 1986; 136: 834-836.

79. Mills PK, Newell GR, Johnson DE. Testicular cancer associated with employment in agriculture and oil and natural gas extraction. Lancet 1984; 1:207-10.

80. McDuffie HH, Quail J, Ghosh S et al. Host factors, occupation and testicular cancer in Saskatchewan, Canada: 1979-2002. J Agric Saf Health 2007; 13:247-58.

81. Kelleher C, Newell J, MacDonagh-White C et al. Incidence and occupational pattern of leukemias, lymphomas, and testicular tumors in Western Ireland over an 11-year period. J Epidemiol Community Health 1998; 52:651-6.

82. Pollan M, Gustavsson P, Cano MI. Incidence of testicular cancer and occupation among Swedish men gainfully employed in 1970. Ann Epidemiol 2001; 11:554-62.

83. Guo J, Pukkala E, Kyyronen P et al. testicular cancer, occupation, and exposure to chemical agents among Finnish men in 1971-1995. Cancer Causes Control 2005; 16:97-103.

84. Garland FC, Gorham ED, Garland CF et al. Testicular cancer in US Navy personnel. Am J Epid 1988; 127:411-4.

85. Haughey BP, Graham S, Brasure J et al. The epidemiology of testicular cancer in upstate New York. Am J Epidemiol 1989; 130:25-36.

86. Sewell CM, Castle SP, Hull HF. Testicular cancer and employment in agriculture, and oil and natural gas extraction. Lancet 1984; 1:553.

87. Walschaerts M, Muller A, Auger J et al. Environmental, occupational and familial risks for testicular cancer: A hospital-based case-control study. Intl J Androl 2007; 30:222-9.

88. Dieckmann KP, Pichlmeier U. Clinical epidemiology of testicular germ cell tumors. World J Urol 2004; 22:2.

89. Hayes H. Excess of Seminomas Observed in Vietnam Service U.S. Military Working Dogs. Journal of the national cancer Institute. Vol. 82, No. 12. June 20, 1990: 1042-1046.

90. Méndez Gallart R, Ríos Tallón J, Mateu Capó G, et al. Microlitiasis testicular. Significado clínico e implicaciones terapéuticas. Actas Urol Esp 24 (10): 832-835. 2000.

91. Bach AM, Hann LE, Shi W, et al. Is there an increased incidence of contralateral testicular cancer in patients with intratesticular microlithiasis?. AJR Am J Roentgenol 2003 Feb; 180(2):497-500.

92. Skakkebaek NE. Possible carcinoma in-situ of the testis. Lancet 1972; 2(7776):2516-7.

93. Jhon C. Cheville. Clasificación y anatomía patológica de los tumores testiculares de células germinales y del estroma. Clínicas de Urología de Norteamérica. Vol 3/1999, pag 629-641.

94. Algaba F. Tumores del testículo. In: Atlas de patología de los tumores urogenitales. Barcelona 1991; 251-303.

95. Steiner H, Gozzi C, Verdorfer I, et al. Metastatic spermatocytic seminomaan extremely rare disease. Eur Urol 2006; 49:183-6.

96. Emil A. Tanagho, Jack W. McAninch. Smith's general urology. Editorial McGraw-Hill, 17th ed.

97. Delanouy. Tumores de testiculo. Actas de reuniones clínicas Medwave Año I, $\mathrm{n}^{\circ} 11$, noviembre 2001.

98. Leiva O. Tumores del testículo. En Urología Vesalio. Editores O. Leiva y Resel, ENE Ediciones, Madrid, 1992; 495-519.

99. Kennedy BJ. Testis cancer. Clinical signs and symptoms. In: Comprehensive textbook of genitourinary oncology. Vogelganz, N.J.; Scardino, P.T.; Shipley, W.U. et al. Lippincott Williams \& Wilkins. 2a Edición. Philadelphia. Pag. 877-923. 2000.

100. Sandeman TF, Symptoms and early management of germinal tumors of the testis. Med J Aust 1979; 2:821. 


\section{Seminoma: puesta al día}

101. Kay R. Prepuberal testicular tumor registry. Urol Clin North Am 1993; 20(1):1-5

102. Mai et al. Younger age-at-diagnosis for familial malignant testicular germ cell tumor. Fam Cancer 2009; 8(4):451-6.

103. Bosl GJ, Goldman A, Lange PH et al. Impact of delay in diagnosis on clinical stage of testicular cancer. Lancet 1981; 2-970.

104. Prout GR, Griffin PP, Testicular tumor. Delay in diagnosis and influence on survival. Am Fam Physician 1984; 29-205.

105. Bree RL, Hoang DT, Scrotal ultrasound. Clin North Am 1996; 34: 1183-1205.

106. Tessler FN, Tublin ME, Rifkin MD, Ultrasound assesment of testicular and paratesticular masses. J Clin Ultrasound 1996; 24:423-436.

107. Hricak H, Hamm B, Kim B. Testicular tumors and tumorlike lesions. Imaging of the scrotum. New York. Raven Press, 1995; 49-88.

108. White PM, Howard CW, Best J et al. The role of the computer tomographic examination of the pelvis in the management of testicular germ cell tumours. Clinical Radiology 1997; 52: 124-129.

109. Wood A, Robson N, Tung KT et al. Pattems of supradiaphragmatic metastasesin testicular germ cell tumours. Clinic Radiology 1996; 51: 273-276.

110. Cremerius U, Wildberger JE, Borchers $\mathrm{H}$ et al. Does positron emission tomography using 18-fluoro2-desoxyglucosa improve clinical sating of testicular cáncer? Results of a study in 50 patiens. Urology 1999; 54: 900-904.

111. Stanton GF, Bosl GJ, Vugrin D et al. Treatment of patients with advanced seminoma with cyclophosphamide, bleomycin, actinomycin D, vinblastine and cisplatin (VAB6) Proc Am Soc Clin Oncol 1983; 2:1.

112. Boyle LE, Samuels ML. Serum LDH activity and isoenzyme patterns in nonseminomatous germinal (NSG) testis tumors. Proc Am Soc Clin Oncol 1997; 18:278.

113. Javadpour M. Multiple biochemical tumor markers in seminoma. A doubleblind study. Cancer 1983;52(5):887-9.

114. Brazell WE, Whitmore WF Jr, Clinical significance of biological markers: Memorial Hospital experience. Semin Oncol 1979; 6:48.

115. Javadpour N. The role of biologic tumour markers in testicular cancer. Cancer 1980; 45(7 Suppl):1755-61.

116. Sobin LH, Gospodariwicz M, Wittekind C. TNM classification of malignant tumors. In: UICC International Union Against Cancer. ed. 7 New York, NY: Wiley-Blackwell; 2009; 249-54.

117. Edge SB, Byrd DR, Compton CC, et al. AJCC Cancer Staging Manual. 7th ed. New York, NY: Springer 2010, pp 469-78.

118. International Germ Cell Cancer Collaborative Group. International Germ Cell Consensus Classification: a prognostic factor-based staging system for metastatic germ cell cancers. J Clin Oncol 1997; 15: 594.

119. Warde P, Specht L, Horwich A, et al. Prognostic factors for relapse in stage I seminoma managed by surveillance: a pooled analysis. J Clin Oncol 2002 Nov; 20(22):4448-52.

120. Bokemeyer C, Schmoll HJ. Treatment of clinical stage I testicular cancer and a possible role for new biological prognostic parameters. J Cancer Res Clin Oncol 1996; 122:575-84.

121. Albers P, Siener R, Kliesch S, et al. German Testicular Cancer Study Group. Risk factors for relapse in clinical stage I nonseminomatous testicular germ cell tumours: results of the German Testicular Cancer Study Group Trial. J Clin Oncol 2003 Apr; 21(8):1505-12.

122. Som A, Zhu R, et al. Recurrent seminomas: clinical features and biologic implications. Urologic Oncology: Seminars and Original Investigations 2012;30(4):494-501.

123. Einhorn LH. Curing metastatic testicular cancer. Proc Natl Acad Sci USA 2002; 99:4592-5.

124. Richardson LC et al. Testicular cancer: a narrative review of the role of socioeconomic position from risk to survivorship. Urologic Oncology: Seminars and Original Investigations 30. 2012: 95-101.

125. Abern, MR, Dude AM.; Coogan CL. Marital status independently predicts testis cancer survival-an analysis of the SEER database. Urologic Oncology: Seminars and Original Investigations, Volume 30, issue 4. July-August, 2012, p. 487-493.

126. Kollmannsberger C, Tyldesley S, Moore C, et al. Evolution in management of testicular seminoma: population-based outcomes with selective utilization of active therapies. Oncol $2011 \mathrm{Apr}$; 22(4):808-14.

127. Jones RH, Vasey PA. Part I: testicular cancer-management if early disease. Lancet Oncol 2003; 4:730-737.

128. Martin JM, Joon DL, $\mathrm{Ng} \mathrm{N}$ et al. Towards individualised radiotherapy for stage I seminoma. Radiother Oncol 2005; 76:251-256

129. Vossen CY, Horwich A, Daugaard G et al. Patterns of care in the management of seminoma stage I: results from a European survey. BJU Int 2012 Mar 12.

130. Francis R, Bower M, Brunström G et al. Surveillance for stage I testicular Germ cell tumors: results and cost benefit analysis of management options. Eur J Cancer 2000; 36:1925-1932

131. Bauduceau O, Souleau B, Le-Moulec S et al. Radiothérapie des séminomes testiculaires de satde I: étud rétrospectiveet revue de la littérature. Cancer/ Radiothérapie 2003; 7:386-394

132. Schoffski P, Höhn N, Kowalski R et al. Health-related quality of life (QoL) in patients with seminoma stage I treated with either adjuvant radiotherapy (RT) or two cycles of carboplatinum chemotherapy (CT): results of a randomized phase III trial of the German Interdisciplinary Working Party on Testicular Cancer. ASCO Annual Meeting Proceedings. Part 1. J Clin Oncol. 2007; 25 Suppl 18S:5050).

133. Aparicio J, Germà JR, García del Muro X, et al. Risk-adapted management for patients with clinical stage I seminoma: the Second Spanish Germ Cell Cancer Cooperative Group study. J Clin Oncol. 2005; 23(34):8717-23.

134. Horwich A, Alsanjari N, A'Hern R et al. Sureillance folowing orchiectomy for satge I testicular seminoma. Br J Cancer 1992; 65: 775-778.

135. Von der Masse $\mathrm{H}$ et al. Surveillance following orchiectomy for satge I seminoma of the testis. Eur J Cancer 1993; 29a(14):1931-4.

136. Choo R, Thomas G, Woo T, et al. Long-term outcome of postorchiectomy surveilance for stage I testicular seminoma. Int J Radiat Oncol Biol Phys 2005; 61(3):736-740.

137. Fossa SD, Horwich A, Russell JM et al. Optimal planning target volume for stage I testicular seminoma: A Medical Research Council Testicular Tumor Working Group randomized trial. J Clin Oncol 1999; 17:1146.

138. Jones WG, Fossa SD, Mead GM, et al. A randomized trial of two radiotherapy schedules in the adjuvant treatment of stage I seminoma (MRC TE 18). Eur J Cancer 2001; 37 Suppl 6:S157.

139. Oliver RT, Mead GM, Rustin GJ, Joffe JK, Aass N, Coleman R, et al Randomized trial of carboplatin versus radiotherapy for stage I seminoma: mature results on relapse and contralateral testis cancer rates in MRC TE19/EORTC 30982 study (ISRCTN27163214). J Clin Oncol 2011; 29:957-62.

140. Travis LB, Curtis RE, Storm H et al. Risk of second malignant neoplasms among long-term survivors of testicular cancer. J Natl Cancer Inst 1997; 89:1429-39.

141. Huddart RA, Norman A, Shahidi M et al. Cardiovascular disease as a long-term complication of treatment for testicular cancer. J Clin Oncol 2003; 21 (8): 1513-23.

142. Meinardi MT, Gietema JA, van der Graaf WT et al. Cardiovascular morbidity in long-term survivors of metastatic testicular cancer. J Clin Oncol 2000; 18:1725-32.

143. Chung PWM, Gospodarowicz MK, Panzarella T et al. Stage II testicular seminoma: patterns of recurrence and outcome of treatment. Eur Urol. 2004;45:754-60, discussion 759-60.

144. García-del-Muro X, Maroto P, Gumà J, Sastre J, López Brea M, Arranz JA et al. Chemotherapy as an alternative to radiotherapy in the treatment of stage IIA and IIB testicular seminoma: a Spanish Germ Cell Cancer Group Study. J Clin Oncol 2008;26:5416-21).

145. Aparicio J, Sastre J, Germà JR, Isla D. SEOM clinical guidelines for diagnosis and treatment of testicular seminoma (2010). Clin Transl Oncol 2011 Aug; 13(8):560-4.

146. Bachner M., Loriot Y, Gross-Goupil M, et al. 2-18 fluoro-deoxy-glucose positron emission tomography (FDG-PET) for postchemotherapy seminoma residual lesions: a retrospective validation of the SEMPET trial. Ann Oncol 2012; 23: 59-64.

147. Wiliams SD, Brich R, Einhorn LH, et al: Treatment of disseminated Germcell tumors with cisplatin, bleomycin and either vinblastine or etoposide. $\mathrm{N}$ Engl J Med 1987; 316(23): 1435-1440

148. Loehrer PJ, Sr, Brich R, Williams SD et al.: Chemotherapy of metastatic seminoma: the Southeastern Cancer Study Group experience. J Clin Oncol 1987; 5(8): 1212-1220

149. Herr HW, Sheinfeld J, Puc HS et al. Surgery for a postchemotherapy residual mass in seminoma. J Urol 1997; 157(3): 860-862

150. Schultz SM, Einhorn, LH, Conces DJ Jr. Et al.: Management of postchemotherapy residual mass in patients with advanced seminoma; Indiana University experience. J Clin Oncol 1989;7(10):1479-1503.

151. Richie J: Simultaneous bilateral tumors with unorthodox management. World J Urol 1984; 2: 74. 